\title{
Associated Credit Risk Contagion and Spillover Effect Based on Supply Chain Buy-Back Guarantee Contract
}

\author{
Xiaofeng Xie $\mathbb{D},{ }^{1,2}$ Yang Yang $\mathbb{D},{ }^{3}$ Kai Xu, ${ }^{1,4}$ and Zongfang Zhou ${ }^{1}$ \\ ${ }^{1}$ School of Management and Economics, University of Electronic Science and Technology of China, Sichuan, China \\ ${ }^{2}$ General Education Department, Chengdu Neusoft University, Sichuan, China \\ ${ }^{3}$ School of Economics Mathematics, Southwestern University of Finance and Economics, Sichuan, China \\ ${ }^{4}$ School of Tourism and Economic Management, Chengdu University, Sichuan, China \\ Correspondence should be addressed to Xiaofeng Xie; xiexiaofeng@nsu.edu.cn
}

Received 23 November 2018; Revised 5 April 2019; Accepted 5 May 2019; Published 10 June 2019

Academic Editor: Ioannis T. Christou

Copyright (c) 2019 Xiaofeng Xie et al. This is an open access article distributed under the Creative Commons Attribution License, which permits unrestricted use, distribution, and reproduction in any medium, provided the original work is properly cited.

\begin{abstract}
We take the supply chain with a supplier and a retailer as the research objects and study the contagion and spillover effect of the associated credit risk in the supply chain under the scenario of the buy-back guarantee contract. The associated credit risk in the supply chain refers to the phenomenon that the credit default of the retailer causes the credit default of the supplier or increases the probability of default. The buy-back guarantee in the supply chain refers to the assumption by the retailer of the supplier's buy-back contract as a financing mechanism. At present, the buy-back guarantee has become a new channel of contagion for the associated credit risk in the supply chain. Under the dual Stackelberg game analysis framework of the lending institutions, suppliers, and retailers, this paper clarifies the contagion mechanism of associated credit risk in the supply chain under the condition of the buyback guarantee and constructs mathematical models to explore the contagion and spillover effect of the associated credit risk in the supply chain. The results show that, under the condition of the buy-back guarantee, the contagion effect of the associated credit risk in the supply chain has trigger thresholds, and the probability of triggering the contagion effect is related to the retailer's order quantity, supplier's wholesale price, and product's market price. The contagion effect is positively affected by the buy-back rate, production costs, and loan interest rates and negatively affected by the product's market price. In contrast, the degree of buy-back guarantee aggravates the negative spillover effect of the associated credit risk and raises the risk level of lending institutions.
\end{abstract}

\section{Introduction and Literature Review}

Under the traditional financing model, it is more difficult for SMEs (Small and medium-sized enterprises) to access financing services from banks due to their lack of a sufficient credit rating and assets. To improve the credit level of SMEs and ameliorate the overall profitability of the supply chain, a supply chain financial model was developed in which the core enterprises provide loan guarantees for SMEs. Simultaneously, credit risk default events stemming from loan guarantees emerge one after another, indicating that the credit risk contagion effect of such credit bundling (loan guarantees) cannot be underestimated [1-3]. In 2011, the "Guarantee Circle" crisis in Wenzhou, China, severely affected the development of Wenzhou's private economy. In 2012, Tianyu Construction Co., Ltd. in Zhejiang province went bankrupt, creating a crisis in enterprises in the "Mutual Guarantee Circle". In 2013, the solar energy giant, Suntech Group, went bankrupt and reorganized, affecting a number of related enterprises that offered loan guarantees. In 2017, the Qixing Group was completely shut down and incurred debts as high as tens of billion dollars, causing several related, dependent companies to experience financial difficulties. These crisis events indicate that, in the associated credit relationship formed by the loan guarantees, once some credit subjects are in a credit crisis, the credit risks will be transmitted and diverge to mimic a "Domino Card Effect", and they will be circulated, transmitted, amplified, and possibly evolved in regional and systemic financial risks in related subject groups.

The buy-back guarantee in the supply chain refers to the financing mechanism in which the retailer uses the 
supplier's buy-back contract as a loan guarantee. Through the buy-back guarantee, the supplier (the core enterprise) can enable the retailer (SMEs) to obtain the necessary loan funds, thereby improving the overall benefits of the supply chain. In fact, when the market demand is in good condition, the retailer generally does not default. At this time, the buy-back guarantee model not only enables the retailer to obtain funds from the lending institutions to enhance its sales ability, but it can also increase the order quantity from the supplier, in turn improving the efficiency of the supply chain. However, when market demand is insufficient, the decline in retailer sales performance will increase the retailer's credit risk. At this time, the supplier needs to implement the buy-back guarantee obligation and undertake the costs of the buy-back guarantee (such as buy-back product costs, transportation and inventory costs, and resale costs of buybacked products, etc.), which will occupy part of the supplier's cash and may result in an increased default probability of the supplier to their lending institutions. Thus, although the buy-back guarantee model partially alleviates the retailer's financing dilemma, the supplier shares some of the retailer's credit risk and forms the associated credit risk in the supply chain. The associated credit risk in the supply chain refers to the phenomenon that the retailer's default causes the supplier to default on credit or increases the probability of default, thus revealing the contagion effect between the supplier and retailer's credit risk. At present, the buy-back guarantee has become a new contagion channel of associated credit risk in the supply chain. Once the contagion of the associated credit risk in the supply chain is triggered, it will have a negative impact on supply chain enterprises and related lending institutions.

The Asian financial crisis in 1997, the global financial crisis in 2008, and the European debt crisis in 2011 show that credit risks of enterprises, individuals, and governments are contagious to financial institutions. In reality, there is a widespread credit correlation between enterprises and financial institutions, which directly affects the risk level of financial institutions [4]. In 2016, the world's Top 500 Bohai Steel demonstrated debt default, with a debt scale of 30 billion dollars, involving 105 financial institutions. In 2017, many expired loans in Dandong Port were overdue, including the Bank of China and many involved state-owned banks, causing severe losses. In 2018, the HNA Group was mired in a capital crisis with a total debt size of 91 billion dollars, and the National Development Bank was the group's largest creditor. In 2017, the International Monetary Fund (IMF) indicated that more than $20 \%$ of American companies were at risk of default, which would have a fatal impact on American financial institutions and even the economy. Therefore, from the perspectives of supply chain enterprises (internal) and lending institutions (external), it is of great theoretical value and practical significance to analyze the contagion of the associated credit risk in the supply chain under the buy-back guarantee mode, which can reduce the harm of the associated credit risk in the supply chain and control the risk of lending institutions.

We use the contagion effect and spillover effect to characterize the contagion characteristics of the associated credit risk in the supply chain from both internal and external perspectives. The contagion effect describes the contagion of the associated credit risk in the supply chain from the perspective of the internal supply chain, which refers to the influence of the retailer's credit risk on the supplier's credit risk. The stronger the contagion effect, the greater the contagiousness of the associated credit risk to the supplier. The spillover effect describes the contagion of the associated credit risk in the supply chain from the perspective of the external supply chain, which refers to the impact of the associated credit risk in the supply chain on lending institutions. The stronger the spillover effect, the greater the contagiousness of the associated credit risk to lending institutions.

In research of supply chain-associated credit risk contagion, credit risk contagion under the trade credit financing model has received substantial interest. Raddatz [5] found that trade credit may spread and amplify a single credit risk. Jacobson and Schedvin [6] indicated that the probability of the supplier's default is positively related to the trade credit limit he provides. Xie et al. [7] showed that the downstream retailer's trade credit default will impact the upstream supplier's income level, thereby increasing her credit risk. Based on the structural model, by adding the impact of trade credit to the jump items in the process of asset value diffusion, Yang (2011) discussed the contagion of trade credit risk in terms of the default risk of enterprises in the supply chain. However, compared with most of the existing literature using the trade credit financing model, this paper takes the buyback covenant as a financing mechanism for the retailer to guarantee loans from lending institutions.

In terms of the spillover effect of the associated credit risk, Tamakoshi and Hamori [8] and Nikkinen et al. [9] constructed the VAR model to test the cross-border spillover effect of stock market risk during the financial crisis. Billio and Getmansky [10] studied the interval spillover effects of risk contagion in financial institutions such as banks. Relevant studies have rarely analyzed the spillover effects of enterprise credit risk on lending institutions. Only Tong et al. [11] have studied the spillover effects of SMEs' credit risk on shadow banks. However, Tong et al. [11] only interpret the impact of the overall credit risk of SMEs on shadow banks from a macro perspective, without specifically describing the mechanism underlying the influence of enterprise credit risk on the risk level of shadow banks, let alone the impact of credit risk contagion among enterprises on shadow banks. Since the impact of enterprise credit risk on lending institutions is closely related to the intensity of enterprise default and the loan losses caused by enterprise default $[12,13]$, commercial banks usually use the nonperforming loan rate to measure the loan risk. Thus, enterprise credit risk is closely related to the loan risk of the lending institutions. Therefore, unlike Tong et al. [11], who used financing dependence to quantify the impact of SMEs on lending institutions, this paper uses the total loan risk of lending institutions to measure the spillover effect of the associated credit risk in the supply chain.

In terms of buy-back mode, the inventory pledge financing decision under the buy-back guarantee and supply 
chain operation decision of buy-back coordination have been widely addressed by scholars. Regarding the inventory pledge, the financing decision under the buy-back guarantee, representative research concerns a pledge rate commensurate with the bank's risk tolerance according to the simplified idea from Jarrow and Turnbull [14]. First, Buzacott and Zhang [15] introduced retailer production decisions into bank credit decision-making, and they established a bank pledge rate game model that belongs to the nature of the newsvendor. Yi and Zhou [16] established a dual Stackelberg game model to study the supply chain enterprise operation and bank credit decisions under the core enterprise buy-back guarantee. The above research explores the bank credit decision and risk sharing under the buy-back guarantee from different perspectives, but it does not analyze the impact of buyback on the credit risk of the guarantee enterprise from the perspective of risk contagion. In the buy-back coordination of operation decisions in the supply chain, Padmanabhan [17] believes that the reason for the prevalence of buy-back, in reality, is that the buy-back strategy can weaken the risks faced by retailers, protect manufacturers' product brands, and facilitate structural competition strategic needs; Lau et al. [18] and Hsieh et al. [19] and Arcelus et al. [20] have demonstrated that the optimal appropriate buy-back strategy can coordinate the supply chain to ensure the overall profit of the supply chain; Ruiz-Benitez et al. [21] considered the customer's behavior and studied the buy-back contract to coordinate the supply chain and the profit distribution among members of the supply chain; Chen et al. [22] explained why suppliers are willing to provide retailers with buy-back guarantees from the perspective of value creation in the supply chain. The related research mainly focuses on the impact of buy-back on the overall benefit of the supply chain, but it does not discuss supply chain risk sharing and risk contagion under the buy-back mechanism.

Thus far, research on associated credit risk based on the buy-back guarantee is still very rare. With the help of previous research foundations, this paper considers the two-echelon supply chain under capital-constraint, and the retailer considers the supplier's buy-back contract as a financing guarantee mechanism. Under the dual Stackelberg game of the lending institutions, supplier, and retailer, this paper establishes theoretical models to study the contagion and spillover effect of associated credit risks in the supply chain. Compared with previous research, the main contributions of this paper are as follows. First, considering the behavior interaction between supply chain enterprises and lending institutions, we integrate the operation strategies of supply chain enterprises and loan strategies of lending institutions under the buyback guarantee. Second, we theoretically verify the risk transmission and coordination role of the buy-back guarantee mechanism. Third, we reveal the contagion mechanism of the associated credit risk in the supply chain and provide a theoretical analytical framework for studying the associated credit risk contagion in the supply chain under the buy-back guarantee. Fourth, we depict the internal and external contagion characteristics of the associated credit risk in the supply chain and offset the deficiency of the existing research on credit risk contagion, which mostly focuses on internal contagion.

\section{Problem Description and Symbol Definition}

2.1. Problem Description. This paper considers a two-echelon supply chain consisting of a supplier (upstream core enterprise) and a newsvendor-like retailer (downstream SMEs) that are all subject to capital constraint (see [23-28]). The supplier (she) provides products for the retailer (he) to sell, and neither the supplier nor the retailer has initial funding [29]. The risk-neutral retailer has a single opportunity to order prior to the selling season (time 0 , the ordering and production time) a product from the risk-neutral supplier to satisfy the uncertain demand (time 1, the selling season) [30]. Due to the existence of the production lead time (such as automobiles, steel products, etc.), the supplier needs to purchase the raw materials to organize production in advance after receiving the order information from the retailer. In the ordering process, the retailer requires financing to achieve his own optimal order quantity. In the production process, the supplier requires financing to achieve the production of the order.

In many emerging economies worldwide, SMEs often struggle to gain support from large formal financial institutions due to severe information asymmetries and the imperfections of the financial system, which is more serious in the financial system dominated by state-owned enterprises [31, 32]; (Cressy, 1997). Lin and Sun [33] have found that informal financial institutions are widespread in developing countries because of the lack of transparency of information in SMEs, resulting in the lack of effective access to information by formal financial institutions and often a failure to provide sufficient guarantees or collateral. As a result, SMEs can only choose small and medium-sized financial institutions or private lending institutions and pay higher financing costs [30, 34-36]. In addition, in an imperfect financial environment, many financial institutions attach rigid guarantee requirements when lending to SMEs, and this role is often played by core enterprises in the supply chain $[37,38]$.

This paper assumes that there are two lending institutions, Formal and Informal, in the capital market, among which Formal is a general commercial bank and Informal is a lending institution that mainly serves SMEs (such as small and medium-sized commercial banks, private lending institutions, etc.). To increase the retailer's credit level and enhance the overall profitability of the supply chain, the supplier, as the core enterprise, promises to the lending institution Informal buy-back retailer's unsold products, for which the proportion is $l$ at the wholesale price $w$, to share the loan risk of Informal. Since Informal is a lending institution that mainly serves SMEs, it is willing to provide the retailer with the financing services under the buy-back guarantee of the core enterprise (Yi et al. 2011). At the beginning of the sales season, the retailer orders $q$ products at the wholesale price $\mathrm{w}$ and pays a certain amount of upfront payments $C_{0}$ $\left(C_{0}<c q, c\right.$ represents marginal costs for the supplier). The supplier acquires finances from the commercial bank Formal to purchase raw materials and organize production. The supplier's funding sources include the retailer's upfront payments $C_{0}$ and the financing from the commercial bank Formal. 
TABle 1: Sequence of Events and Decision Protocol.

Time 0: Ordering and production

(1) Supplier and retailer sign order contract $(w, q)$

(2) Retailer, which is short on cash, applies to the

lending institution Informal for loan wq

(3) Informal provides loan wq to the retailer under the

supplier's buy-back guarantee at an interest rate of $r_{r}$

(4) Retailer pays the upfront payments $C_{0}$ to the

supplier

(5) Supplier finances cq $-C_{0}$ from the commercial bank Formal due to insufficient production capital with an interest rate of $r_{s}$

(6) Supplier organizes the production and delivers the order after the production is completed

Time 1: End of the selling season

(1) If the demand is insufficient, the supplier buy-backs

the retailer's unsold product under the buy-back

guarantee contract $(w, l)$, where $w$ is the buy-back

price and $l$ is the buy-back rate

(2) Retailer repays the loan obligations of Informal. If

the retailer's income is not sufficient to pay Informal's

loan obligations, then the retailer defaults and Informal receives the retailer's residual income

(3) Supplier repays the loan obligations of Formal. If the supplier's income is not sufficient to pay Formal's loan obligations, then the supplier defaults and Formal receives the supplier's residual income
Drawing on the general setup of Kouvelis and Zhao $[26,30]$ and Yang and Birge [39], the strategic interactions between the supplier and retailer are modeled as a Stackelberg game where the supplier acts as a leader and the retailer as a follower. The decision sequence of events is shown in Table 1 .

(1) Before the sales season (time 0), the supplier sets the wholesale price $w$, and the retailer determines the order quantity $q$ according to the wholesale price and the forecast of the market demand $x$. Since the retailer's initial cash flow is 0 , the retailer launches a loan application to the lending institution Informal to pay for the goods. Under the buy-back guarantee of the supplier, Informal provides a loan wq to the retailer with a cost of $r_{r}$. The buy-back guarantee contract is $(w, l)$, of which $w$ is the buy-back price and $l$ is the buyback rate. When the retailer receives the loan from Informal, he pays the upfront payments $\mathrm{C}_{0}$ to the supplier. After the supplier receives the upfront payments $C_{0}$, the insufficient portion is required to apply for a loan $c q-C_{0}$ from the commercial bank Formal at an interest rate of $r_{s}$. When the product is finished, the supplier delivers the order $q$ and the retailer pays the remaining $\mathrm{wq}^{-} \mathrm{C}_{0}$

(2) At the end of the sales season (time 1), the retailer sells $\min [q, x]$ at a fixed retail price $p>w$ in the retail market, and the supplier buy-backs the unsold product $[q-x]^{+}$at wholesale price $w$ and buy-back rate $l$, and $[q-x]^{+}=$ $\max [q-x, 0]$. Next, the supplier and retailer repay their loan obligations to the lending institutions. The retailer repays the loan obligations $\min \left[\mathrm{p} \min [\mathrm{q}, \mathrm{x}]+\mathrm{wl}[\mathrm{q}-\mathrm{x}]^{+}, \mathrm{wq}\left(1+\mathrm{r}_{\mathrm{r}}\right)\right]$ to Informal. The supplier repays loan obligations $\min \left[w q-C_{0}-\right.$ $\left.w l[q-x]^{+},\left(c q-C_{0}\right)\left(1+r_{s}\right)\right]$ to Formal.

The above assumptions can be seen as an extension of the Buzacott and Zhang [15] and Yi and Zhou [16] models, which integrates the operational decisions of enterprises in the supply chain and the financing decisions of lending institutions through the decision-making interactions of the lending institutions, the supplier and retailer. However, they only consider the retailer's capital constraint, and we assume that both the supplier and retailer face capital constraint $[26,30]$. The interaction among the lending institutions, the supplier, and retailer is a dual Stackelberg game. The first game exists between the lending institutions and the supply chain enterprises (the supplier and retailer), and the second game exists between the supplier and retailer. In the first game, the lending institution is the leader, and the supply chain enterprises are the follower. In the second game, the supplier is the leader, and the retailer is the follower.

In reality, the interest rate of lenders is often related to the credit quality of borrowers. The higher the borrower's credit risk, the higher the interest rate on the loan he has to pay [40]. In general, the retailer's credit risk is greater than that of the supplier. Thus, the interest rate established by the lending institution Informal should be greater than the interest rate established by the commercial bank Formal, i.e., $r_{r}>r_{s}$ [30]. However, when the buy-back rate is large, the lending institution Informal may reduce the interest rate due to the lower default risk of the retailer. Nevertheless, due to the corresponding increase in supplier default risk, the commercial bank Formal may raise the interest rate, which may lead to $r_{r} \leq r_{s}$. Therefore, this paper assumes that the loan interest rate includes two cases, $r_{r}>r_{s}$ and $r_{r} \leq r_{s}$.

Drawing on the assumptions of Kouvelis and Zhao [26] and Jia et al. [41], our other modeling assumptions are as follows:

Assumption 1(A1). The upfront payments paid by the retailer to the supplier remain constant.

Assumption 2 (A2). No information asymmetry, i.e., all parameters are common knowledge to the supplier, retailer, and lending institutions.

Assumption 3 (A3). Due to the constraints of market demand during the loan cycle, this paper does not take into consideration the residual value of the supplier buy-backed products.

Assumption 4 (A4). The retailer and supplier will repay their loan obligations to the extent possible.

Assumption 5 (A5). The market demand $x$ for the newsvendor market is uncertain, its cumulative distribution function 
TABLE 2: Notation.

\begin{tabular}{|c|c|}
\hline \multicolumn{2}{|c|}{ Symbols } \\
\hline $\begin{array}{l}p \text { : Product market price, unchanged throughout the } \\
\text { loan season }\end{array}$ & $\begin{array}{l}x: \text { Production market demand during the loan season, } \\
x \in(0,+\infty)\end{array}$ \\
\hline$w:$ Wholesale price of the supplier, $0<w<p$ & $c:$ Marginal cost of the supplier, $0<c<w$ \\
\hline$q$ : Retailer's order quantity, $q \geq 0$ & $\mathrm{E}\left(\pi_{r}\right):$ The retailer's expected profit \\
\hline $\begin{array}{l}C_{0} \text { : Upfront payments to the supplier when the retailer } \\
\text { orders the products, } 0 \leq C_{0}<C q \text {, especially, when } \\
\text { retailer's order quantity } q=0 \text {, then, } C_{0}=0 \\
r_{s}, r_{r}: \text { Interest rates of the lending institutions Formal } \\
\text { and Informal for providing financing services to the } \\
\text { supplier and the retailer respectively, } r_{s}, r_{r} \geq r_{f}\end{array}$ & $\begin{array}{l}\mathrm{E}\left(\pi_{s}\right) \text { : The supplier's expected profit } \\
l: \text { Buy-back rate of the retailer's unsold products negotiated } \\
\text { between the supplier and the lending institution Informal, } \\
l>0 \text {. Assume that after the sales cycle, the residual value } \\
\text { of the unit product that the retailer has not buy-backed is } 0\end{array}$ \\
\hline $\begin{array}{l}Z_{s}: \text { Credit default event of the supplier, } Z_{s}=1 \\
\text { represents the supplier's default, and } Z_{s}=0 \text { represents } \\
\text { no breach of contract }\end{array}$ & $\begin{array}{l}\tau \text { : Probability of contagion of associated credit risk caused } \\
\text { by the retailer's default, } \tau=\operatorname{Prob}\left(\mathrm{Z}_{s}=1 \mid \mathrm{Z}_{r}=1\right)\end{array}$ \\
\hline $\begin{array}{l}Z_{r}: \text { Credit default event of the retailer, } Z_{r}=1 \text { represents } \\
\text { the retailer's default, } Z_{r}=0 \text { represents no breach of } \\
\text { contract }\end{array}$ & $\begin{array}{l}\delta_{s}: \text { Threshold of market demand at the time of the } \\
\text { supplier's default } \\
\delta_{r}: \text { Threshold of market demand at the time of the }\end{array}$ \\
\hline $\begin{array}{l}\delta_{s}: \text { Threshold of market demand at the time of the } \\
\text { supplier's default; }\end{array}$ & retailer's default \\
\hline
\end{tabular}

is $\mathrm{F}(\mathrm{x})$, and the probability density is $f(x)$, among which $F(x)$ is continuous, differentiable, and strictly increasing, and $\bar{F}(x)=1-F(x)$

2.2. Symbol Definition. The notation is summarized in Table 2. In general, we use subscripts $s, r$ for supplier, retailer, respectively.

\section{Analysis of the Contagion Mechanism of Associated Credit Risk in the Supply Chain}

Since demand is uncertain, the default risk of the retailer mainly stems from this uncertainty. The buy-back guarantee contract provided by the supplier to the retailer makes it possible for the retailer's credit risk to infect the supplier, resulting in the contagion effect of the associated credit risk in the supply chain. At the end of the sales season, whether the loan obligations of the lending institution Informal can be effectively recovered depends on the market demand of the product and the buy-back rate. When the market demand for the product is insufficient, if the retailer's sales revenue is insufficient to pay Informal's loan obligations, then the retailer defaults. If the supplier buy-backs the retailer's unsold products and the remaining revenue is still not sufficient to pay the loan obligations of the commercial bank Formal, the supplier will also face default. Under the buy-back guarantee contract, the retailer can raise the optimal order quantity by financing from Informal, thereby enhancing the overall income of himself and the whole supply chain. However, once market demand conditions deteriorate, the retailer's misjudgment on market will result in a large number of unsalable products. As a guarantor, the supplier is obliged to buy-back the retailer's unsold products at the wholesale price, which may result in tighter funds of the supplier's to increase her credit risk.

Let $\delta_{s}$ and $\delta_{r}$ be the demand thresholds for the supplier and retailer to repay the loan obligations, respectively. In this paper, we call $\delta_{s}$ and $\delta_{r}$ default thresholds for the supplier and retailer, respectively.

For the retailer, if the sales revenue at the end of the sales season $p \min [q, x]+w l[q-x]^{+}<w q\left(1+r_{r}\right)$, then the retailer is insolvent to default on Informal. Specifically, when demand is insufficient, if $p x+w l(q-x)<w q\left(1+r_{r}\right)$, i.e., $x<w q(1+$ $\left.r_{r}-l\right) /(p-w l)$, the retailer will default. Thus

$$
\delta_{r}=\frac{w q\left(1+r_{r}-l\right)}{p-w l}
$$

In this case, the terminal cash flow after the supplier pays the retailer buy-back costs $w \mathrm{l}(q-x)$ is, wq $-\mathrm{C}_{0}-\mathrm{wl}(\mathrm{q}-\mathrm{x})$. If $w q-C_{0}-w l(q-x)<\left(c q-C_{0}\right)\left(1+r_{s}\right)$, then $x<(q[c(1+$ $\left.\left.\left.r_{s}\right)+w(l-1)\right]-C_{0} r_{s} / w l\right) / w l$, and the supplier will choose to default. Thus

$$
\delta_{s}=\frac{q\left[c\left(1+r_{s}\right)+w(l-1)\right]-C_{0} r_{s}}{w l}
$$

Lemma 6. The threshold of the retailer's default $\delta_{r}$ and the threshold of the supplier's default $\delta_{s}$ should fit

$$
\begin{array}{ll}
\delta_{s}<\delta_{r}<q, & \text { if } \varphi\left(r_{s}, r_{r}\right)>0 \\
\delta_{r} \leq \delta_{s}<q, & \text { if } \varphi\left(r_{s}, r_{r}\right) \leq 0
\end{array}
$$

where $\varphi\left(r_{s}, r_{r}\right)=w^{2} l\left(1+r_{r}-l\right)-(p-w l)\left(c\left(1+r_{s}\right)+w(l-1)\right)$.

Proof. Let the deviation of the default threshold $\Delta \delta(q)=\delta_{r}-$ $\delta_{s}=\left(q \varphi\left(r_{s}, r_{r}\right)+(p-w l) C_{0} r_{s}\right) /(p-w l) w l$, where $\varphi\left(r_{s}, r_{r}\right)=$ $w^{2} l\left(1+r_{r}-l\right)-(p-w l)\left(c\left(1+r_{s}\right)+w(l-1)\right)$, When $q=0$, apparently we have, $\mathrm{C}_{0}=0$. Then, $\Delta \delta(\mathrm{q})=0$. For $\varphi\left(r_{s}, r_{r}\right)>$ $0, \partial(\Delta \delta(q)) / \partial q>0$, then $\Delta \delta(q)$ is a monotonically increasing function of $[0,+\infty)$. Thus, $\Delta \delta(q)>\Delta \delta(0)=0$, i.e., $\delta_{s}<\delta_{r}$. The retailer acts as a rational economic person, and $w(1+$ $\left.r_{r}\right)<p$ and thus, $w\left(1+r_{r}-l\right) /(p-w l)<1$. That is, $\delta_{r}=$ $q\left(w\left(1+r_{r}-l\right) /(p-w l)\right)<q$. Additionally, $\delta_{s}<\delta_{r}$, then 


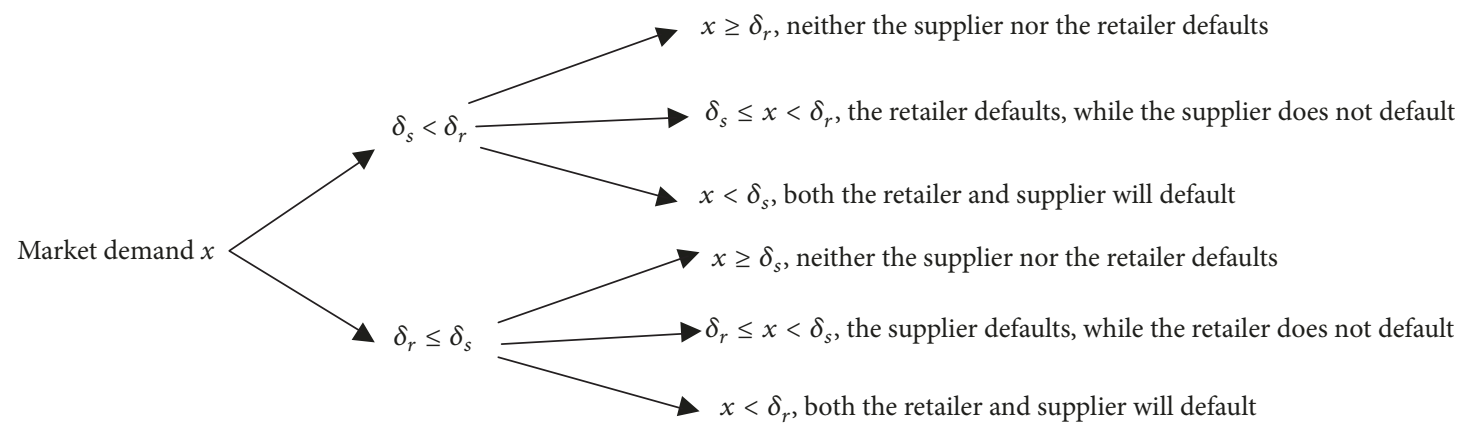

FIGURE 1: All default paths for the supplier and retailer.

$\delta_{s}<\delta_{r}<q$. Similarly, the second case $\delta_{r} \leq \delta_{s}<q$ can be certified.

For the general supply chain financing model (such as trade credit), if the retailer does not default, the supplier will often not default [42]. At this point, the retailer's default threshold is greater than the supplier. Under the buy-back guarantee, because the retailer's repayment of Informal's loan obligations is partly derived from the supplier's buy-back costs, which may cause the supplier's funds to be tight and prevent repayment of Formal's loan obligations. Thus, there may be cases where the retailer does not default and the supplier defaults. At this point, the retailer default threshold is smaller than the supplier. Therefore, under the buy-back guarantee, the supplier and retailer's default thresholds are $\delta_{s}<\delta_{r}$ and $\delta_{r} \leq \delta_{s}$, respectively, for the two cases. In the following two scenarios, $\delta_{s}<\delta_{r}$ and $\delta_{r} \leq \delta_{s}$, we analyze the micromechanism of credit risk transmission from retailer to supplier.

Proposition 7. When $\delta_{s}<\delta_{r}$ and $x<\delta_{s}$, or when $\delta_{r} \leq \delta_{s}$ and $x<\delta_{r}$, the retailer's credit risk is transmitted to the supplier, resulting in the contagion effect of the associated credit risk in the supply chain.

Figure 1 shows all cases in which the supplier and retailer default. For $\delta_{s}<\delta_{r}$, if $x<\delta_{r}$, the retailer defaults. If the market demand also satisfies $x<\delta_{s}$, then the supplier also defaults; i.e., when $x<\delta_{s}$, the retailer's default will lead to the supplier's default. When $\delta_{s} \leq x<\delta_{r}$, although the retailer defaults, the funds after the supplier buy-backs satisfy $w q-C_{0}-w l(q-x)>\left(c q-C_{0}\right)\left(1+r_{s}\right)$, indicating the supplier's remaining funds after she fulfills the buy-back obligation are sufficient to pay her loan, and the supplier does not default. When $\delta_{r} \leq x$, at this time, the market demand is sufficient, and both the retailer and supplier can get better returns to repay the loan, and neither of them will default. For $\delta_{r} \leq \delta_{s}$, when $x<\delta_{r}$, then $x<\delta_{s}$, the retailer's default will inevitably lead to the supplier's default. When $\delta_{r} \leq x<\delta_{s}$, the retailer does not default, but the supplier defaults; when $\delta_{s} \leq x$, neither the supplier nor the retailer defaults in the desirable market demand environment.

By Proposition 7, the retailer's credit risk does not necessarily infect the supplier. The possibility of the contagion effect of associated credit risk in the supply chain is related to the market demand and default threshold of the supplier and retailer. Next, we use the default threshold deviation $(\Delta \delta(q)=$ $\delta_{r}-\delta_{s}$ ) of the supplier and retailer to study the probability of the contagion effect of the associated credit risk in the supply chain (abbreviated as the probability of contagion).

When $\delta_{s}<\delta_{r}$, the bigger (smaller) $\Delta \delta(q)$ is, when " $x<$ $\delta_{r}$ " occurs, then the probability of " $x<\delta_{s}$ " occurring is smaller (bigger), and the default dependence between the supplier and the retailer is weaker (stronger), and the smaller (bigger) the probability that the retailer's credit risk will be transmitted to the supplier. When $\delta_{r} \leq \delta_{s}$, the default of the retailer will inevitably result in the supplier's default. At this time, the probability of contagion is positively related to the retailer's default probability, which is only related to the retailer's default threshold. The larger $\delta_{r}$ is, the greater is the probability of the occurrence of the retailer's default event " $x<\delta_{r}$ ", and the greater is the probability of contagion of the associated credit risk in the supply chain.

Proposition 8. When $\delta_{s}<\delta_{r}\left(\delta_{r} \leq \delta_{s}\right)$, the contagion probability of the associated credit risk in the supply chain is negatively (positively) correlated with q, positively (negatively) correlated with $p$, and negatively (positively) correlated with w.

Proof. (1) For $\delta_{s}<\delta_{r}$, because $\Delta \delta(q)$ is an increasing function of $q$. The retailer increases the order quantity $q$ to augment the default threshold deviation, thereby reducing the contagion probability of the associated credit risk in the supply chain. Therefore, the contagion probability of the associated credit risk in the supply chain is negatively correlated with $q$.

In general, the retailer's order quantity $q$ is an increasing function of the market price $p$ and a decreasing function of the wholesale price $w$. This assumption agrees with scholars such as Chen et al. [22, 43]. Because

$$
\begin{aligned}
& \frac{\partial(\Delta \delta)}{\partial p}=\frac{\partial(\Delta \delta(q))}{\partial q} \cdot \frac{\partial q}{\partial p}>0, \\
& \frac{\partial(\Delta \delta)}{\partial w}=\frac{\partial(\Delta \delta(q))}{\partial q} \cdot \frac{\partial q}{\partial w}<0
\end{aligned}
$$

then the default threshold deviation changes in the same direction as $p$ and in reversed-phase with $w$, indicating that the market price of the product $p$ increases or the wholesale 
price $w$ decreases, which can increase the deviation of the default threshold and reduce the contagion probability of the associated credit risk in the supply chain. Thus, the contagion probability of associated credit risk in the supply chain is negatively correlated with $p$ and positively correlated with w.

(2) For $\delta_{r} \leq \delta_{s}$, because $\partial \delta_{r} / \partial q=w\left(1+r_{r}-l\right) /(p-w l)>$ $0, \partial \delta_{r} / \partial p=-w\left(1+r_{r}-l\right) /(p-w l)^{2}<0, \partial \delta_{r} / \partial w=q p(1+$ $\left.r_{r}-l\right) /(p-w l)^{2}>0$, it can be concluded that the contagion probability of the associated credit risk in the supply chain is positively correlated with $q$, negatively correlated with $p$, and positively correlated with $w$.

The implication of Proposition 8 is that when the retailer's default threshold is greater than the supplier, the supplier will not default as long as the retailer does not default. At this point, the higher the retailer's order quantity and the product market price, the lower the retailer's credit risk, and the lower the possibility of his credit risk transmission to the supplier. Therefore, the supplier can motivate the retailer to increase his order by reducing the wholesale price appropriately. However, when the retailer default threshold is less than that of the supplier, once the retailer defaults, the supplier must default. Even if the retailer does not default, the supplier may default because the buy-back cost is too high. The higher the retailer's order quantity, the lower the market price of the product, the higher the retailer's credit risk, and the higher the possibility of the retailer's credit risk transmission to the supplier. Therefore, the supplier can raise the wholesale price to make the retailer reduce the order quantity, thus reducing the probability of being contagious to the retailer's credit risk.

The following is a discussion of the relationship between the contagion source of credit risk (the retailer's credit risk) and the contagion object (the supplier's credit risk) and the buy-back rate in the supply chain.

Proposition 9. As the buy-back rate l increases, the retailer's credit risk gradually decreases, and the supplier's credit risk gradually increases.

Proof. Because $\partial \delta_{r} / \partial l<0, \partial \delta_{s} / \partial l>0$, then $\delta_{\mathrm{r}}$ is the decreasing function of $l$. Assume $l_{1}<l_{2}$, then $\delta_{r_{1}}>\delta_{r_{2}}$. It can be drawn that $\operatorname{Prob}\left(x<\delta_{r_{1}}\right)>\operatorname{Prob}\left(x<\delta_{r_{2}}\right), \operatorname{Prob}\left(x<\delta_{s_{1}}\right)<$ $\operatorname{Prob}\left(x<\delta_{s_{2}}\right)$ the retailer's credit risk decreases as $l$ increases, and the supplier's credit risk increases as $l$ increases.

Proposition 9 is consistent with our intuition. When the buy-back rate increases, the number of products that the supplier needs to buy-back increases, and the buy-back cost increases. The more money retailers use to repay his loan obligations, the less likely he is to default. In other words, the retailer's credit risk shared by the supplier is increasing, and the supplier's credit risk is increasing accordingly. The buy-back contract, as an effective risk-sharing mechanism, can transfer the uncertainty of the market demand for the newsvendor faced by the retailer to the supplier's credit risk and theoretically verify the risk transmission effect of the buyback contract.

\section{Model Construction of Contagion and Spillover Effect}

The contagion effect refers to the influence of the retailer's credit risk on the supplier, which is the main risk characteristic of the associated credit risk in the supply chain. The uncertainty of the demand market creates the credit risk of the retailer, and the buy-back contract leads to a "Mutual Glory, Mutual Loss" relationship between the retailer and the supplier, which means the associated credit risk presents a contagion effect. Under different internal and external economic environments and financing costs, the intensity of the associated credit risk contagion effects in the supply chain (i.e., the intensity of contagion) is not consistent. To accurately measure the contagion intensity of the associated credit risk in the supply chain and to specifically analyze the influential factors and evolution rules of the associated credit risk contagion intensity in the supply chain, this part will establish the contagion effect model of the associated credit risk contagion in the supply chain under the stochastic demand of the newsvendor market. The model measures the contagion intensity of the retailer's credit risk to the supplier's credit risk after provision by the supplier of the buy-back contract to the retailer.

The spillover effect refers to the impact of the associated credit risk in the supply chain on external lending institutions, which is another important feature of the associated credit risk in the supply chain. The credit relationship and the guarantee chain between the lending institutions and the supply chain enterprises make them constitute a "Credit Community". Once the associated credit risk in the supply chain is contagious, it will quickly spread to lending institutions in the capital market. The spillover effect of the associated credit risk contagion in the supply chain not only has dominant characteristics (such as the failure of the enterprises in the supply chain to repay the loans in full and on time, which will seriously damage the interests of lending institutions, and the loan risk of lending institutions will increase accordingly) but also has invisible characteristics (such as the intensification of the associated credit risk contagion effect in the supply chain, causing social investors to distrust lending institutions, the spread and accumulation of the distrust may trigger a run on the lending institutions, affecting the development of lending institutions and the stability of the capital market). The stronger the spillover effect, the more contagious the associated credit risks in the supply chain to the lending institutions, and the greater the loan risks faced by the lending institutions. Based on the contagion effect model, we establish a spillover effect model to measure the spillover effect of the associated credit risk in the supply chain and analyze the impact of the associated credit risk on the lending institutions in the supply chain.

\subsection{Contagion Effect Model}

Definition 10. The conditional probability $\tau$ of the supplier's default because of the retailer's default is called the contagion intensity of the associated credit risk in the supply chain, i.e., $\tau=\operatorname{Prob}\left(\mathrm{Z}_{s}=1 \mid \mathrm{Z}_{r}=1\right)$. 
Because $\operatorname{Prob}\left(\mathrm{Z}_{r}=1\right)=\operatorname{Prob}\left(x<\delta_{r}\right), \operatorname{Prob}\left(\mathrm{Z}_{s}=1\right)=$ $\operatorname{Prob}\left(x<\delta_{s}\right)$, then,

$$
\tau=\operatorname{Prob}\left(x<\delta_{s} \mid x<\delta_{r}\right)=\frac{\operatorname{Prob}\left(x<\delta_{s}, x<\delta_{r}\right)}{\operatorname{Prob}\left(x<\delta_{r}\right)}
$$

When $\delta_{s}<\delta_{r}$, the contagion intensity of the associated credit risk is simplified to

$$
\tau=\frac{\operatorname{Prob}\left(\mathrm{x}<\delta_{\mathrm{s}}\right)}{\operatorname{Prob}\left(\mathrm{x}<\delta_{\mathrm{r}}\right)}=\frac{\mathrm{F}\left(\delta_{\mathrm{s}}\right)}{\mathrm{F}\left(\delta_{\mathrm{r}}\right)}
$$

When $\delta_{r} \leq \delta_{s}$, the contagion intensity of the associated credit risk reaches the maximum

$$
\tau=\frac{\operatorname{Prob}\left(x<\delta_{s}, x<\delta_{r}\right)}{\operatorname{Prob}\left(x<\delta_{r}\right)}=\frac{\operatorname{Prob}\left(x<\delta_{r}\right)}{\operatorname{Prob}\left(x<\delta_{r}\right)}=1
$$

In the following section, the inverse solution method of the Stackelberg game is used to determine the optimal order quantity of the retailer and the optimal wholesale price of the supplier, subsequently substituting the optimal response function of the retailer and supplier into the expected revenue Equation of the lending institutions Formal and InformalInformal, respectively, to obtain the loan interest rates of Formal and InformalInformal, and finally measuring the contagion intensity of the associated credit risk in the supply chain under the optimal decentralized decision of the supply chain.

4.1.1. The Retailer's Optimal Ordering Strategy. Under the supplier's buy-back guarantee contract, the capital constrained retailer obtains the financing service wq from the lending institution Informal prior to the sales season and accepts the contract provided by the supplier with order quantity $q$ and payments wq. At the end of the sales season, the retailer obtains sales revenue $p \min [q, x]+w l[q-x]^{+}$. and pay loan obligations $\min \left[p \min [q, x]+w l[q-x]^{+}, w q\left(1+r_{r}\right)\right]$ to Informal. The retailer will determine the optimal order quantity to maximize his expected revenue:

$$
\begin{aligned}
\max _{q} E\left(\pi_{r}\right) \\
=E\left[p \min [q, x]+w l[q-x]^{+}-w q\left(1+r_{r}\right)\right] \\
=\int_{0}^{q}(p x+w l(q-x)) f(x) d x \\
\quad+\int_{q}^{+\infty} p q f(x) d x-w q\left(1+r_{r}\right)
\end{aligned}
$$

Proposition 11. Under the supplier's buy-back guarantee, the retailer's optimal order quantity $q^{*}$ is

$$
q^{*}=\bar{F}^{-1}\left(\frac{w\left(1+r_{r}\right)}{P}\right)
$$

Proof. Take the derivative of Equation (8), then $\partial E\left(\pi_{r}\right) / \partial q=$ $p(1-F(q))-w\left(1+r_{r}\right)=p \bar{F}(q)-w\left(1+r_{r}\right)$, and $\partial^{2} E\left(\pi_{r}\right) / \partial q^{2}=$ $\bar{F}(q)+p(\partial \bar{F}(q) / \partial q)=\bar{F}(q)-p F^{\prime}(q) \leq 0$. Thus, the retailer's optimal order quantity $q^{*}$ exists. Assume $\partial E\left(\pi_{r}\right) / \partial q=0$, then $q^{*}=\bar{F}^{-1}\left(w\left(1+r_{r}\right) / P\right)$.
4.1.2. The Supplier's Optimal Wholesale Price Strategy. When the retailer determines his optimal order quantity $q^{*}$, the supplier can follow the retailer's response function $\mathrm{q}^{*}=$ $\overline{\mathrm{F}}^{-1}\left(\mathrm{w}\left(1+\mathrm{r}_{\mathrm{r}}\right) / \mathrm{P}\right)$ to determine her own optimal wholesale price $\mathrm{w}^{*}$. At the begin of the sales season, after receiving the order quantity $q$ and upfront payments $C_{0}$ of the retailer, the supplier finances $\mathrm{cq}-\mathrm{C}_{0}$ from the commercial bank Formal for production, and the interest rate is $r_{s}$. At the end of the sales season, the supplier's sales income is $w q-C_{0}-w l[q-x]^{+}$, and the loan obligations are paid $\min \left[w q-C_{0}-w l[q-\right.$ $\left.x]^{+},\left(c q-C_{0}\right)\left(1+r_{s}\right)\right]$ to the commercial bank Formal. The supplier will choose the optimal wholesale price to maximize her expected revenue:

$$
\begin{array}{rl}
\max _{w} & E\left(\Pi_{s}\right) \\
= & E\left[w q-C_{0}-w l[q-x]^{+}-\left(c q-C_{0}\right)\left(1+r_{s}\right)\right] \\
= & \int_{0}^{q}(w q-w l(q-x)) f(x) d x \\
& \quad+\int_{q}^{+\infty} w q f(x) d x-c q\left(1+r_{s}\right)+C_{0} r_{s}
\end{array}
$$

Proposition 12. After the supplier provides the retailer with a buy-back guarantee contract, the supplier's optimal wholesale price $w^{*}$ is

$$
w^{*}=-\frac{q^{*}}{q^{* \prime}}+c\left(1+r_{s}\right)
$$

Proof. By substituting Equation (9) into Equation (10) and then deriving the $E\left(\Pi_{s}\right)$ about $w$ and taking a value of 0 , $q^{*}+\left[w-c\left(1+r_{s}\right)\right] q^{* \prime}=0$. Thus, $w^{*}=-q^{*} / q^{* \prime}+c\left(1+r_{s}\right)$, $w^{*} \in\left[c\left(1+r_{s}\right)-C_{0} r_{s} / q, p /\left(1+r_{r}\right)\right)$.

4.1.3. The Lending Institution's Loan Strategy. Due to the requirement of risk control of the lending institutions, it may be assumed that the basic expected revenue of the financing services provided by the lending institutions Formal and Informal (i.e., the guaranteed income of the lending institutions) is a risk-free return $\left(r_{f}\right)$, i.e., Formal and Informal can determine the loan interest rates $r_{r}$ and $r_{s}$ using the following Equations:

$$
\begin{aligned}
& w q\left(1+r_{f}\right)=E[\min [p \min [q, x] \\
& \left.\left.+w l[q-x]^{+}, w q\left(1+r_{r}\right)\right]\right] \\
& \left(c q-C_{0}\right)\left(1+r_{f}\right)=E[\min [w q \\
& \left.\left.-C_{0}-w l[q-x]^{+},\left(c q-C_{0}\right)\left(1+r_{s}\right)\right]\right]
\end{aligned}
$$

The first Equation represents the condition under which the interest rate for the retailer receiving the Informal loan should meet, and the second Equation depicts the condition under which the interest rate for the supplier receiving Formal loan should meet. The following are discussed under the condition that the expected revenue of the lending institutions is the basic expected revenue. 
When $x<\delta_{r}$, the lending institution Informal only receives the total sales revenue of retailer $p x+w l(q-x)$. When $x \geq \delta_{r}$, Informal retracts all loan obligations $w q\left(1+r_{r}\right)$, and the first Equation is revised to

$$
\begin{aligned}
& \int_{0}^{\delta_{r}}(p x+w l(q-x)) f(x) d x \\
& \quad+\int_{\delta_{r}}^{+\infty} w q\left(1+r_{r}\right) f(x) d x=w q\left(1+r_{f}\right)
\end{aligned}
$$

Similarly, and the second Equation is converted to

$$
\begin{aligned}
& \int_{0}^{\delta_{s}}\left(w q-C_{0}-w l(q-x)\right) f(x) d x \\
& \quad+\int_{\delta_{s}}^{+\infty}\left(c q-C_{0}\right)\left(1+r_{s}\right) f(x) d x \\
& \quad=\left(c q-C_{0}\right)\left(1+r_{f}\right)
\end{aligned}
$$

Substituting the optimal response function $q^{*}$ and $w^{*}$ for the retailer and supplier and the default threshold $\delta_{r}, \delta_{s}$ into Equation (13) and (14), the interest rates $r_{r}$ and $r_{s}$ of the lending institutions can be calculated by solving the Equations. Furthermore, substituting $r_{r}$ and $r_{s}$ into the above $q^{*}$ and $w^{*}$, the optimal order quantity $q^{*}\left(r_{r}, r_{s}\right)$ and the optimal wholesale price $w^{*}\left(r_{r}, r_{s}\right)$ are calculated and then the retailer's and supplier's default threshold $\delta_{r}=w^{*} q^{*}\left(1+r_{r}-\right.$ $l) /\left(p-w^{*} l\right)$, and $\delta_{s}=\left(q^{*}\left[c\left(1+r_{s}\right)+w^{*}(l-1)\right]-C_{0} r_{s}\right) / w^{*} l$ are calculated. If the probability density of the market demand of the product is known, the contagion intensity $\tau$ of the associated credit risk in the supply chain can be calculated according to the contagion effect model:

$$
\begin{aligned}
& \tau \\
& = \begin{cases}\frac{F\left(\left(q^{*}\left[c\left(1+r_{s}\right)+w^{*}(l-1)\right]-C_{0} r_{s}\right) / w^{*} l\right)}{F\left(w^{*} q^{*}\left(1+r_{r}-l\right) /\left(p-w^{*} l\right)\right)}, & \delta_{s}<\delta_{r} \\
1, & \delta_{r} \leq \delta_{s}\end{cases}
\end{aligned}
$$

4.2. Spillover Effect Model. Based on the previous analysis, to discuss the spillover effect of the associated credit risk in the supply chain, the difference in the total loan risk of the lending institutions with the buy-back guarantee and no buy-back guarantee is used as a substituted variable for the spillover effect of the associated credit risk in the supply chain. To facilitate comparative analysis, it is assumed that when the supplier does not provide a buy-back guarantee contract, the retailer can also obtain the financing service from the lending institution Informal. In addition, since the loan risk faced by the lending institutions is positively related to the credit risk of the credit subject (see $[12,13]$ ), the loan risk of the lending institutions can be assumed to be equal to the credit risk of the credit subject.

In the case of a buy-back guarantee, the total loan risk of the lending institutions is the loan risk of the lending institution Informal (the retailer's credit risk) and the loan risk of the commercial bank Formal (the credit risk that the retailer transmits to the supplier). At this time, the lending institution's overall loan risk is quantified as

$$
\begin{aligned}
\eta & =\operatorname{Prob}\left(\mathrm{Z}_{r}=1\right)+\operatorname{Prob}\left(\mathrm{Z}_{s}=1 \mid \mathrm{Z}_{r}=1\right) \\
& =F\left(\delta_{r}\right)+\frac{\min \left[F\left(\delta_{s}\right), F\left(\delta_{r}\right)\right]}{F\left(\delta_{r}\right)}
\end{aligned}
$$

In the case of no buy-back guarantee (i.e., $l=0$ ), the total loan risk of the lending institutions only consists of the loan risk of the lending institution Informal (the credit risk of the retailer). Because the retailer provides the repayments $w q-C_{0}>\left(c q-C_{0}\right)\left(1+r_{s}\right)$ to the supplier when the order is delivered by the supplier, the supplier does not have credit risk, and the commercial bank Formal correspondingly does not have loan risk. Then, the lending institution's overall loan risk is quantified as

$$
\begin{aligned}
& \begin{array}{l}
\eta^{0}=\operatorname{Prob}\left(\mathrm{Z}_{r}=1\right)=\operatorname{Prob}\left(p x<w q\left(1+r_{r}\right)\right) \\
=\operatorname{Prob}\left(x<\frac{w q\left(1+r_{r}\right)}{p}\right)
\end{array} \\
& \text { Let } \delta_{r}{ }^{0}=w q\left(1+r_{r}\right) / p \text {, then } \\
& \eta^{0}=\operatorname{Prob}\left(\mathrm{Z}_{r}=1\right)=F\left(\delta_{r}{ }^{0}\right)
\end{aligned}
$$

Comparing $\eta^{0}$ and $\eta$, the relationship between the two is not necessarily $\eta^{0}<\eta$, but also depends on the market demand $x$, market price $p$, buy-back rate $l$ and other factors. When the market is in good condition, the buyback guarantee eases the financing constraints faced by the retailer. The optimal order quantity of the retailer increases, the overall profit of the supply chain increases, and the default probability of the supply chain enterprises decreases. Thus, the total loan risk of the two lending institutions may be lower, that is, there may be $\eta \leq \eta^{0}$.

When $\eta-\eta^{0} \leq 0$, the contagion of the associated credit risk in the supply chain has a positive spillover effect, which will further alleviate the financing dilemma of SMEs, improve the overall profitability of the supply chain, and reduce the credit risk of supply chain enterprises, which is conducive to a virtuous circle of credit cooperation between the lending institutions and the financing enterprises. Conversely, when $\eta-\eta^{0}>0$, the contagion of the associated credit risk in the supply chain has a negative spillover effect. The increased loan risk of the lending institutions will then increase the volatility of the financial system.

\section{Contagion and Spillover Effect Numerical Analysis}

The following is a simulation of the above research questions by MATLAB 2017a, specifically analyzing the influential factors, evolution trends of contagion intensity and spillover effect of the associated credit risk in the supply chain.

Drawing on the setting of the demand market distribution of the newsvendor by Yi et al. (2011), Arcelus et al. [20] 
TABLE 3: Loan interest rates, wholesale prices, order quantities and contagion intensities under different buy-back rates.

\begin{tabular}{|c|c|c|c|c|c|c|c|}
\hline$l$ & $r_{s}$ & $r_{r}$ & $w^{*}$ & $q^{*}$ & $\delta_{s}$ & $\delta_{r}$ & $\tau$ \\
\hline 0.2 & 0.1029 & 0.1257 & 5.2077 & 802 & 0 & 555 & 0 \\
\hline 0.3 & 0.0527 & 0.1144 & 5.1684 & 840 & 10 & 548 & 0.0189 \\
\hline 0.4 & 0.0400 & 0.1015 & 5.1914 & 856 & 30 & 526 & 0.0570 \\
\hline 0.5 & 0.0500 & 0.0883 & 5.2505 & 857 & 171 & 493 & 0.3478 \\
\hline 0.6 & 0.0752 & 0.0756 & 5.3317 & 849 & 290 & 449 & 0.6469 \\
\hline 0.7 & 0.1110 & 0.0638 & 5.4266 & 835 & 375 & 375 & 0.9552 \\
\hline 0.8 & 0.1538 & 0.0535 & 5.5261 & 817 & 435 & 320 & 1 \\
\hline 0.9 & 0.2009 & 0.0454 & 5.6276 & 794 & 476 & 221 & 1 \\
\hline 1 & 0.2499 & 0.0405 & 5.7192 & 768 & 504 & 78 & 1 \\
\hline
\end{tabular}

and Kouvelis and Zhao [26], this paper assumes that market demand $x \sim \mathrm{U}[0, D]$, then $f(x)=1 / D, F(x)=x / D$. According to Propositions 11 and 12, the optimal decisions of the retailer and the supplier are as follows:

$$
\begin{aligned}
q^{*} & =\frac{\mathrm{D}}{2}\left(1-\beta c\left(1+r_{s}\right)\right), \\
w^{*} & =\frac{1+\beta c\left(1+r_{s}\right)}{2 \beta},
\end{aligned}
$$

$$
\text { where } \beta=\frac{1+r_{r}}{P}
$$

The retailer's and supplier's default thresholds are

$$
\delta_{r}=\frac{\left(1-\left(\beta c\left(1+r_{s}\right)\right)^{2}\right)\left(1+r_{r}-l\right) D}{2\left[2\left(1+r_{r}\right)-l\left(1+\beta c\left(1+r_{s}\right)\right)\right]}
$$

$$
\tau=\frac{\min \left[\delta_{s}, \delta_{r}\right]}{\delta_{r}}=\min \left[\frac{\left[\beta\left(1+r_{s}\right)(l+1)+l-4\left(C_{0} r_{s} / D\right)-1\right]\left[2\left(1+r_{r}\right)-l\left(1+\beta c\left(1+r_{s}\right)\right)\right]}{l\left(1+\beta c\left(1+r_{s}\right)\right)^{2}\left(1+r_{r}-l\right)}, 1\right]
$$

Thus, the spillover effect of the associated credit risk in the supply chain is expressed as

$$
\eta-\eta^{0}=\frac{\delta_{r}-\delta_{r}{ }^{0}}{D}+\frac{\min \left[\delta_{s}, \delta_{r}\right]}{\delta_{r}}
$$

The model-related parameters are established below to analyze the impact and evolutionary trend of the buy-back rate, product market price, supplier's production cost, and loan interest rate on the contagion intensity of the associated credit risk in the supply chain. Finally, the spillover effect of the associated credit risk in the supply chain is simulated.

5.1. Sensitivity Analysis of the Buy-Back Rate. The operation decision-making of the supply chain and the credit decision of the lending institutions are integrated into a unified framework, and the impact of the buy-back rate on the contagion intensity of the associated credit risk in the supply

$$
\begin{aligned}
& \delta_{s} \\
& =\frac{\left(1-\beta c\left(1+r_{s}\right)\right)\left[\beta c\left(1+r_{s}\right)(l+1)+l-1\right] D-4 C_{0} r_{s}}{2 l\left(1+\beta c\left(1+r_{s}\right)\right)}
\end{aligned}
$$

Equation (13) and Equation (14) are used to obtain the retailer's and supplier's interest rate decision-making equation:

$$
\begin{aligned}
& \delta_{r}^{2}(p-w l) \\
& \quad+2 w q\left[\delta_{r}\left(l-r_{r}-1\right)+D\left(r_{r}-r_{f}\right)\right]=0 \\
& \delta_{s}^{2} w l+2 \delta_{s}\left[q w(1-l)-C_{0}-\left(c q-C_{0}\right)\left(1+r_{s}\right)\right] \\
& \quad+2 D\left(c q-C_{0}\right)\left(r_{s}-r_{f}\right)=0
\end{aligned}
$$

Equation (15) is used to obtain the contagion intensity of the associated credit risk in the supply chain: chain is examined from the perspective of the endogenous loan interest rate. The model parameters are set at $p=8$, $c=3, C_{0}=13, D=3000, r_{f}=0.04$, the buy-back rate $l$ is $0.2-1$, the step length is 0.1 , and the loan interest rate, supplier's optimal wholesale price, retailer's optimal order quantity, and contagion intensity of the associated credit risk in the supply chain are simulated. The simulation numerical results are shown in Table 3. The relationship between the relevant variables and the buy-back rate is shown in Figure 2.

As shown in Figure 2(a), the interest rate of the supplier's loan from the commercial bank Formal is " $U$ "-shaped with the buy-back rate, and the interest rate of the retailer's loan from the lending institution Informal is negatively correlated with the buy-back rate. In particular, when the buy-back rate is less than 0.6 , the retailer's loan interest rate is higher than the supplier's loan interest rate, which is in line with general knowledge. When the buy-back rate exceeds 0.6 , the supplier's loan interest rate is higher than the retailer's loan 


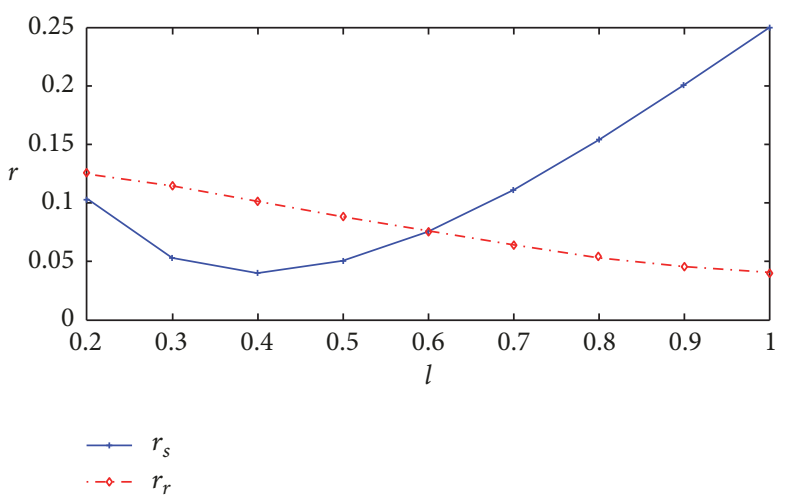

(a) Relationship between the buy-back rate and the loan interest rate

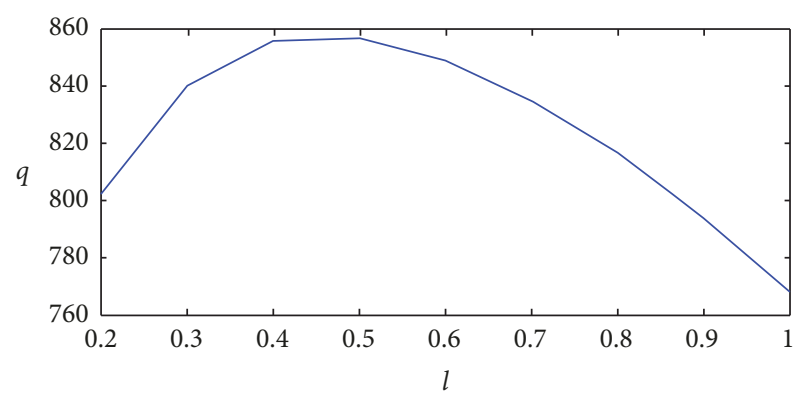

(c) Relationship between the buy-back rate and the retailer's order quantity

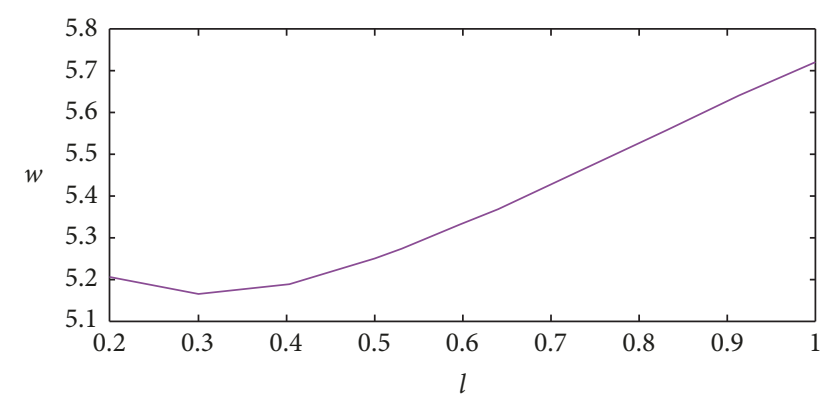

(b) Relationship between buy-back rate and the supplier's wholesale price

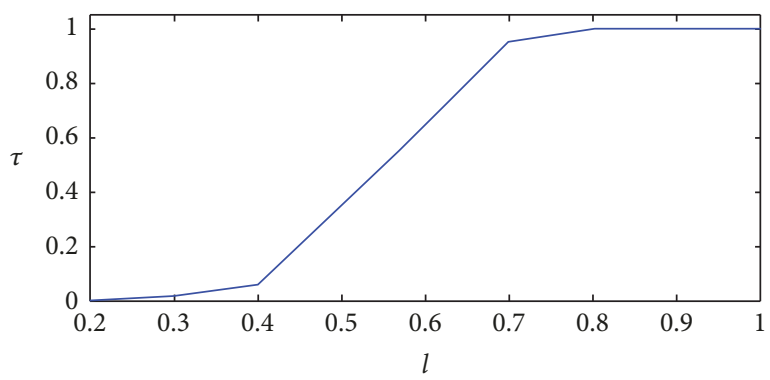

(d) Relationship between the buy-back rate and the contagion intensity

FIGURE 2: Interest rate, wholesale price, order quantity, and contagion intensity under different buy-back rates.

interest rate. Figures 2(b), 2(c), and 2(d) show that, with the gradual increase in the buy-back rate, the wholesale price of the supplier increases after a small decrease, and the order quantity of the retailer is " $U$ "-shaped. The contagion intensity continues to rise and remains constant after the buy-back rate exceeds 0.8 (its value is equal to the upper limit of the contagion intensity 1 ). The research shows that the buyback contract plays a role in the coordination mechanism to a certain extent, which can reduce the financing cost of the supply chain enterprises and increase the order quantity of the retailer. When the buy-back rate reaches a certain value (in this case, buy-back rate reaches 0.4 in Figure 2(d)), as the financing cost of the supplier increases greatly, the wholesale price increases significantly, the order quantity of the retailer decreases correspondingly, and the contagion intensity of the associated credit risk in the supply chain increases significantly. In fact, when the market price is fixed, the increase in the buy-back rate will increase the wholesale price, the retailer's profit will decrease, and the probability of the retailer's default will increase accordingly. Since the supplier's default is caused by the retailer's default, the increase in the default probability of the retailer will raise the probability of the supplier's default, and the contagion intensity of the associated credit risk in the supply chain will also rise.

The findings presented in Figure 2(a) are consistent with those of Tirole [40]; that is, lending institutions will claim different risk premiums according to the credit quality of the enterprises. The greater the credit risk of an enterprise, the higher the risk premium required by the lending institutions. For lending institutions, the buy-back rate measures the strength of the supplier's loan guarantee, and a higher buyback rate means that the supplier has a more full-value guarantee. According to Figure 2(a), the risk premium level of the lending institution's capital can be obtained. The red line denotes the retailer's linear risk premium, and the blue "U"-shaped curve indicates that the supplier's risk premium first decreases and then increases. Figure 2(b) implies that wholesale prices are higher at higher buy-back rates, indicating that the supplier requires higher risk premiums to assume on more risks $[44,45]$. Figure 2(c) shows that the supplier can use buy-back contracts to guide the retailer to increase his order quantity. Conversely, the buy-back rate also reflects the allocation of the retailer's credit risk between the supplier and lending institution Informal. A higher buy-back rate indicates that the supplier shares a higher credit risk. Therefore, the contagion intensity of the associated credit risk displays an increasing trend (Figure 2(d)).

5.2. Sensitivity Analysis of the Product Market Price. To analyze the impact of the product market price on the contagion intensity of the associated credit risk in the supply chain, the model parameters are set to $l=0.6, c=3, C_{0}=13$, $D=3000, r_{f}=0.04$, the market price $\mathrm{p}$ is $4-14$, and the step length is 2 . The simulation results are shown in Table 4 . The relationship between the relevant variables and the market price is shown in Figure 3. 
TABLE 4: Loan interest rates, wholesale prices, order quantities and contagion intensities under different market prices.

\begin{tabular}{lccccccc}
\hline$p$ & $r_{s}$ & $r_{r}$ & $w^{*}$ & $q^{*}$ & $\delta_{s}$ & $\delta_{r}$ \\
\hline 4 & 0.0789 & 0.0541 & 3.5157 & 221 & 191 & 186 & 388 \\
6 & 0.0991 & 0.0705 & 4.4511 & 618 & 351 & 0.903 \\
8 & 0.0752 & 0.0756 & 5.3317 & 849 & 290 & 449 & 0.6469 \\
10 & 0.0533 & 0.0773 & 6.2212 & 989 & 178 & 469 & 0.3797 \\
12 & 0.0421 & 0.0779 & 7.1295 & 1079 & 69 & 476 \\
14 & 0.0403 & 0.0781 & 8.0534 & 1140 & 0 & 479 \\
\hline
\end{tabular}

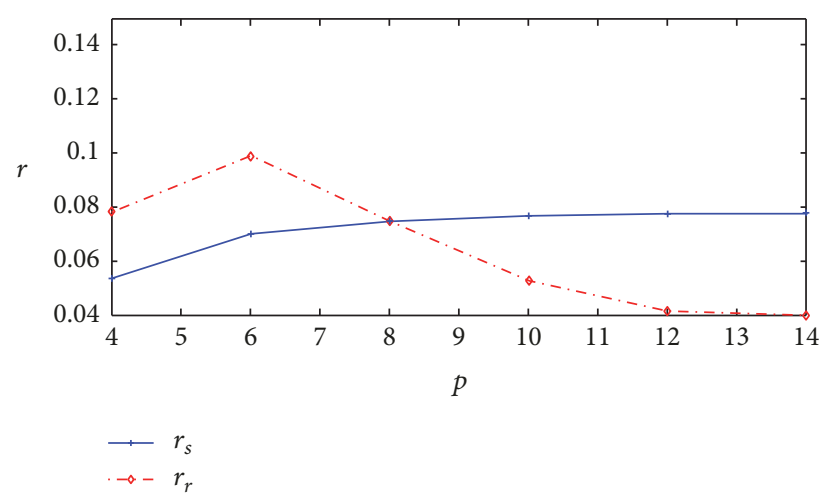

(a) Relationship between the market price and the loan interest rate

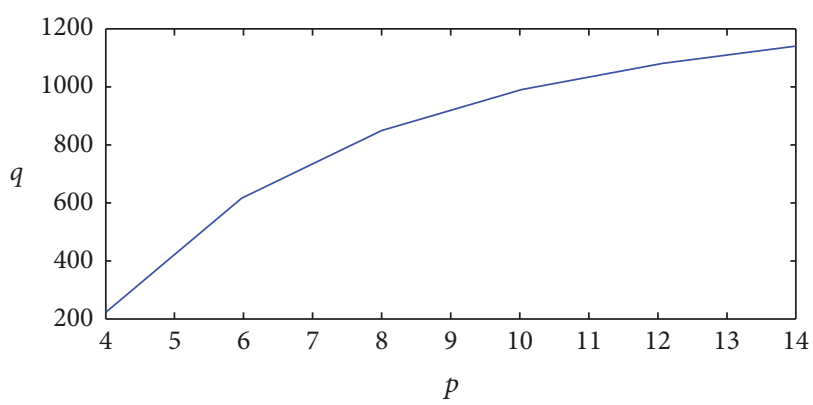

(c) Relationship between the market price and the retailer's order quantity

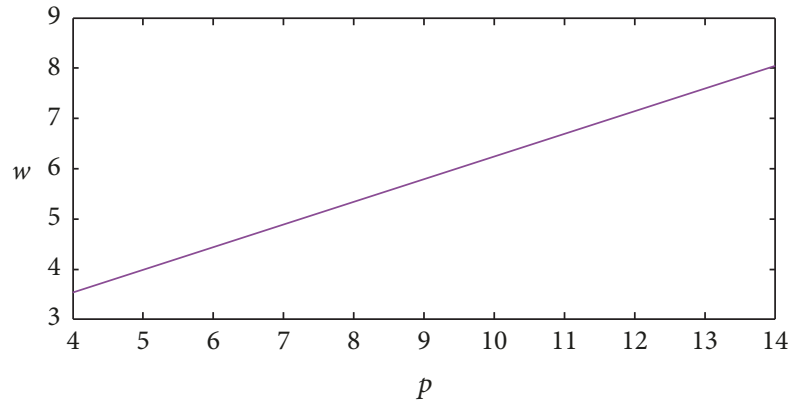

(b) Relationship between the market price and the supplier's wholesale price

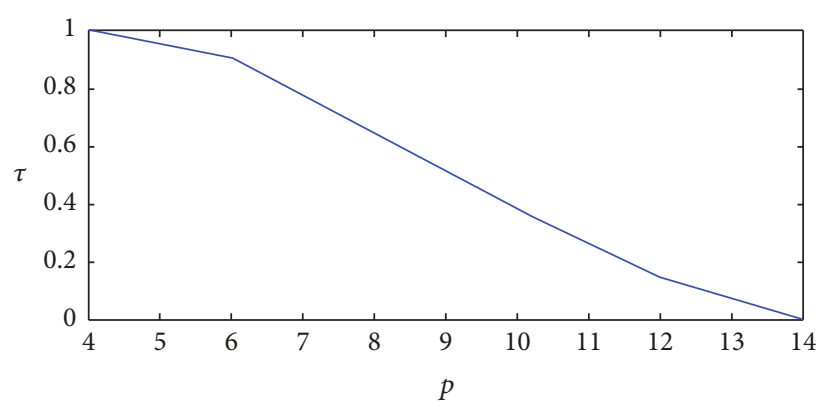

(d) Relationship between the market price and the contagion intensity

FIGURE 3: Interest rate, wholesale price, order quantity, and contagion intensity under different market prices.

Figure 3(a) shows that the increase in the market price of the product significantly raises the credit level of the retailer. The retailer's loan interest rate plummets, but the impact on the supplier's loan interest rate is subtle. The specific underlying reason is that the direct beneficiary of the increase in market price of the product is the retailer, and it is still difficult to balance the credit risk under the high buy-back rate based on the small improvement in the supplier's income, resulting in high interest rate levels. As the market price of products continues to increase, the wholesale price and order quantity continue to rise, and the contagion intensity exhibits an approximately linear decrease (see Figures 3(b), $3(\mathrm{c})$, and $3(\mathrm{~d}))$. When the production cost and the buy-back rate are certain, the increase in the market price of the product will augment the expected revenue of the retailer, thereby increasing the order quantity, and the retailer's revenue will be improved. The smaller the probability of default by the retailer, the less likely the supplier to default, and the less contagion intensity the associated credit risk in the supply chain.

Generally, the level of market prices measures the external market environment of the supply chain. Higher market prices indicate a better external market environment. In our model, all uncertainty was derived from the market. Figure 3(a) shows that, with the increase in supply chain level, the market advantage of supply chain enterprises gradually weakens. Of course, when the market environment improves, the credit risk of the supplier and retailer is more diluted by the market (Figure 3(d)). However, this dilution depends to a certain extent on the allocation of risk by enterprises in the supply chain; therefore, the contagion intensity curve does not decrease linearly.

5.3. Sensitivity Analysis of Production Cost. To analyze the impact of production cost on the contagion intensity of the associated credit risk in the supply chain, assuming other 
TABLE 5: Loan interest rates, wholesale prices, order quantities and contagion intensities under different production costs.

\begin{tabular}{ccccccrc}
\hline$c$ & $r_{s}$ & $r_{r}$ & $w^{*}$ & $q^{*}$ & $\delta_{s}$ & $\delta_{r}$ \\
\hline 2 & 0.0421 & 0.0779 & 4.753 & 1079 & 69 & 476 & 0.1454 \\
3 & 0.0752 & 0.0756 & 5.3317 & 849 & 290 & 449 & 0.6469 \\
4 & 0.0991 & 0.0705 & 5.9348 & 618 & 351 & 388 & 0.9030 \\
5 & 0.0977 & 0.0631 & 6.5068 & 406 & 300 & 299 & 1.0047 \\
6 & 0.0789 & 0.0541 & 7.0314 & 221 & 191 & 186 \\
7 & 0.0518 & 0.0441 & 7.5124 & 59 & 57 & 57 \\
\hline
\end{tabular}

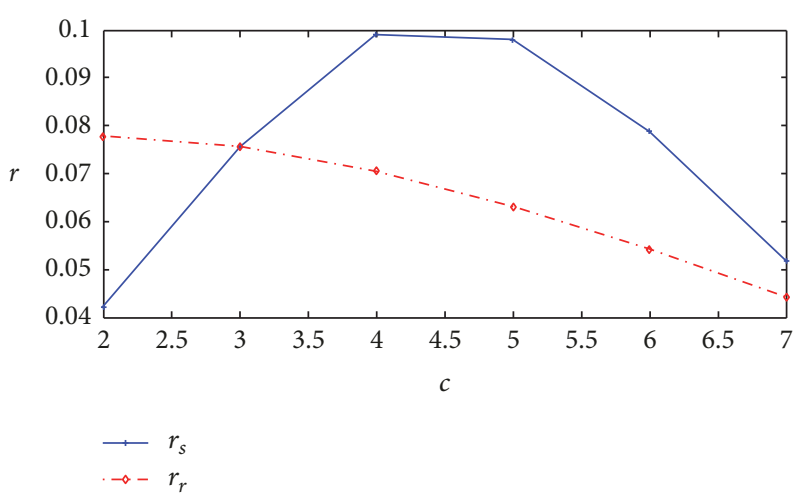

(a) Relationship between production cost and the loan interest rate

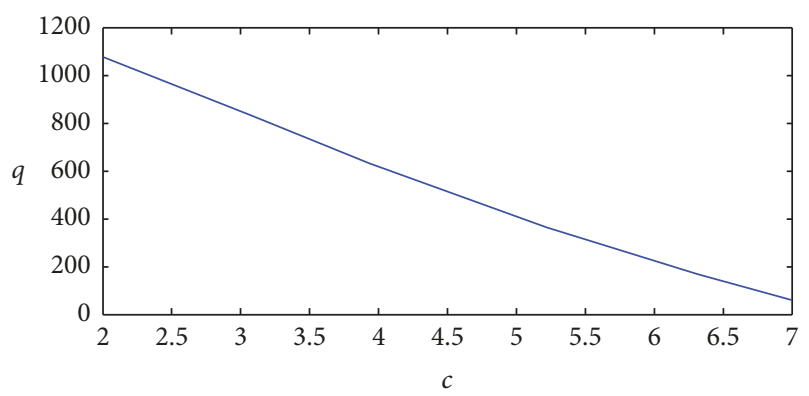

(c) Relationship between production cost and the retailer's order quantity

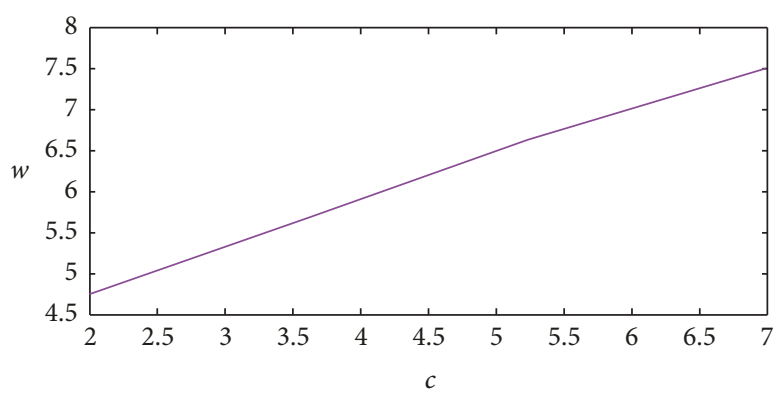

(b) Relationship between production cost and the supplier's wholesale price

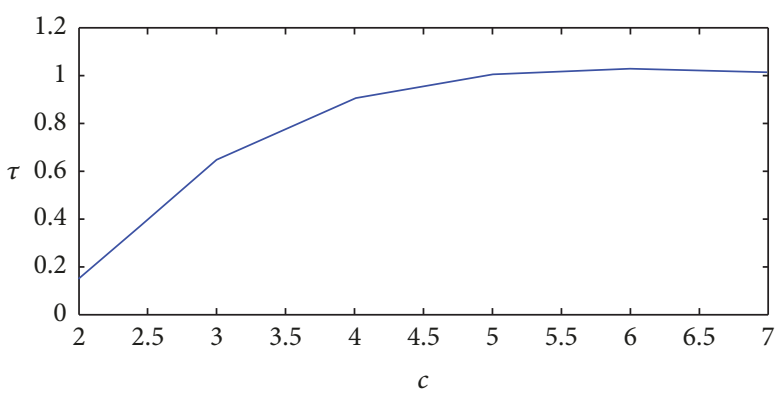

(d) Relationship between production cost and the contagion intensity

FIGURE 4: Interest rate, wholesale price, order quantity, and contagion intensity under different production costs.

parameters remain unchanged, production cost $c$ assumes a value of $2-7$, and the step length is 1 . The simulation numerical results are shown in Table 5. The relationship between relevant variables and production cost are shown in Figure 4.

As shown in Figure 4(a), the supplier's loan interest rate has an inverted "U"-shaped relationship with the cost of production, and the retailer's loan interest rate decreases with the increase in production cost. When the product market price and buy-back rate are certain, the higher the production cost, the higher the supplier's wholesale price, and the lower the retailer's profit. The shrinking profit margins increase the probability of the retailer's default, which leads to a corresponding increase in the probability of the supplier's default, and greater contagion intensity of the associated credit risk in the supply chain.

The implication of Figure 4 is that the increase in production cost increases the credit risk of the supplier and retailer as a whole, resulting in a monotonous increase in the intensity of contagion. The upper concave curve of contagion intensity shows that when the buy-back rate is fixed, the risk of rising costs is mainly borne by the upstream supplier. Interestingly, Figure 4(a) shows that the impact of production cost on the supplier and retailer is inconsistent. First, for the supplier, a rising production cost will have two effects. On one hand, the capital effect, production of the same products, needs more money, and then the need for more loans. However, for lending institutions, more loans means greater risk exposure, raising the interest rate of the supplier loans [46]. The converse is the income effect, in which the rising cost augments the wholesale price, reduces the overall market demand of the product and the supplier's output, and the supplier's capital demand, then declines, causing the loan interest rate to fall. The supplier's interest rate level is determined by the trade-off between these two factors, so her interest rate presents an inverted " $U$ "-shaped relationship. For the retailer, 
TABLE 6: The total values of credit risk $(\eta)$ and spillover effects $\left(\eta-\eta^{0}\right)$ of the lending institutions under different buy-back rates.

\begin{tabular}{lccccccccccc}
\hline$l$ & 0 & 0.1 & 0.2 & 0.3 & 0.4 & 0.5 & 0.6 & 0.7 & 0.8 & 0.9 & 1 \\
\hline$\eta$ & 0.1993 & 0.1735 & 0.1851 & 0.2017 & 0.2323 & 0.5120 & 0.7965 & 1.0860 & 1.1066 & 1.0738 & 1.0260 \\
$\eta-\eta^{0}$ & & -0.0141 & 0.0024 & 0.0331 & 0.3127 & 0.5972 & 0.8868 & 0.9073 & 0.8745 & 0.8267 & 0.4918 \\
\hline
\end{tabular}

Note: When the buy-back rate $l=0$, the total amount of risk is the total credit risk of the lending institutions when no associated credit risk is contagious.

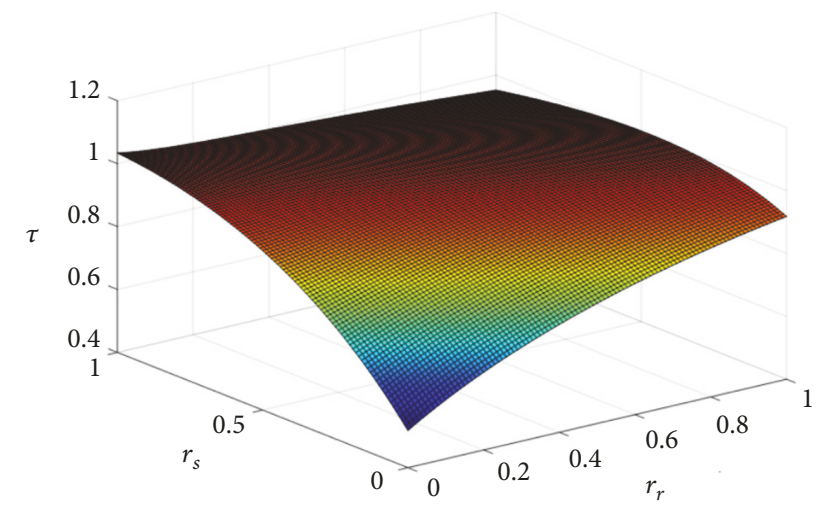

FIGURE 5: Relationship between the loan interest rate and contagion intensity.

the main effect of rising production costs is the income effect, which leads to a linear decrease in retailer interest rates. Generally, rising costs are most disadvantageous to the supplier, which essentially mirrors the redistribution of credit risk and benefits in the supply chain.

5.4. Sensitivity Analysis of Loan Interest Rate. To analyze the impact of the loan interest rate on the contagion intensity of the associated credit risk in the supply chain, the buyback rate is set to $l=0.6$, and the remaining parameters are unchanged. Based on the exogenous loan interest rate perspective, the simulation is adjusted so the loan interest rates of the supplier and retailer gradually increase from 0 to 1 , and the results are shown in Figure 5.

In Figure 5, the relationship between the loan interest rate of the supplier and retailer and the contagion intensity of the associated credit risk in the supply chain are included in the same coordinate plane, which shows the evolution of the contagion intensity under different loan interest rates. As shown in Figure 5, under certain conditions, the loan interest rates of the supplier and retailer increase concomitantly, and the contagion intensity of the associated credit risk in the supply chain continues to increase. A new finding is that as the retailer's loan interest rate decreases and the supplier's loan interest rate increases, the contagion intensity of the associated credit risk in the supply chain will continue to grow. This finding suggests that, in actual operations, the supplier will transfer the high loan interest rate to the retailer through higher wholesale prices, and the reduction in retailer's sales revenue will increase the probability of default, thereby enhancing the contagion intensity of the supplier's associated credit in the supply chain.

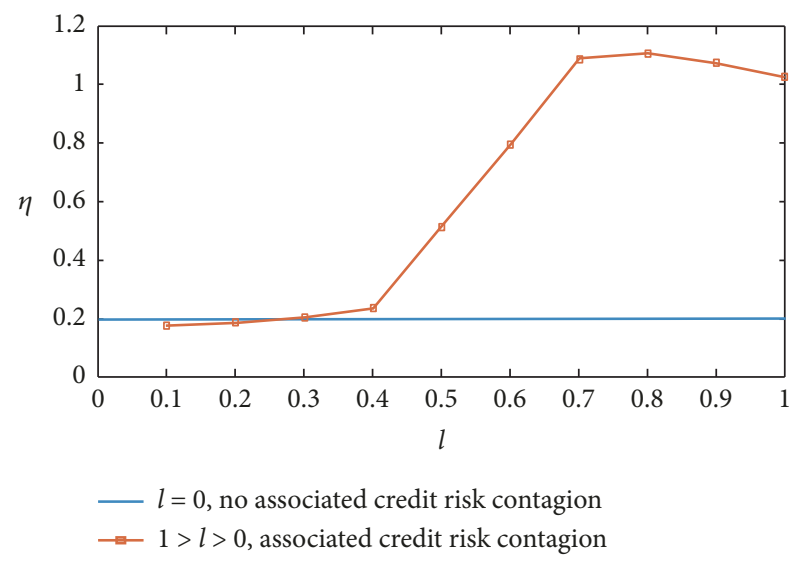

FIGURE 6: Impact of associated credit risk contagion on the total loan risk of the lending institutions in the supply chain.

Financing decision-making $\left(r_{s}, r_{r}\right)$ of lending institutions to supply chain enterprises determines the intensity of contagion to a certain extent. Figure 5 shows an overall strategy for the supply chain by the lending institutions, and the contagion intensity reaches a minimum when the strategy is selected. Although the lending institution Informal provides loans to the retailer under the buy-back guarantee of the supplier, the credit systems of the two lending institutions are separate: commercial banks Formal supply loans to the supplier, and lending institutions Informal provide loans to the retailer. However, Figure 5 illustrates that, from the perspective of risk control, it is beneficial and helpful for lending institutions to account for the relationship between upstream and downstream enterprises in the supply chain as a whole. It also illustrates the informative role of the supply chain for lending institutions. To some extent, it supports the research results of Cressy and Olofsson [47] and Hu and Huang [38].

5.5. Spillover Effect of Associated Credit Risk in the Supply Chain. To analyze the impact of the associated credit risk contagion in the supply chain on the overall loan risk of the lending institutions, the spillover effect model is simulated. The related parameters in the model are set to $p=8, w=4.5$, $c=3, C_{0}=13, D=3000, r_{f}=0.04$ the simulation data is shown in Table 6 , and the simulation results are shown in Figure 6.

As shown in Figure 6, the total loan risk of the lending institutions under the no buy-back guarantee is approximately 0.2 . In the case of a buy-back guarantee, the total loan risk of the lending institutions within the buy-back rate range $[0.1,0.3]$ is less than 0.2 , and the total loan risk 
when the buy-back rate is greater than 0.3 is greater than 0.2 . This result shows that, within the buy-back rate range $[0.1,0.3]$, the associated credit risk in the supply chain has a positive spillover effect. As the buy-back rate increases, the positive spillover effect becomes weaker. When the buy-back rate is greater than 0.3 , the associated credit risk contagion in the supply chain has a negative spillover effect. As the buy-back rate increases, the negative spillover effect becomes stronger. In other words, the level of buy-back rate reinforces the negative impact of the associated credit risk on lending institutions.

The simulation results shown in Figure 6 verify the theoretical analysis of the spillover effect model and further verify the grim fact that, in reality, loan guarantees cause severe losses to many enterprises and related lending institutions. In fact, a certain degree of buy-back guarantee helps reduce the overall credit risk of lending institutions and promote the stable development of the capital market. However, the high level of buy-back will increase the level of risk for the guarantor and the lending institutions, which may cause great economic losses to the guarantor and the lending institutions. This result emphasizes the following. For lending institutions, in the context of supply chain, risk management within a single is not sufficient and to obtain the full benefit, lending institutions must apply risk management across the supply chain [46]. The lending institutions should pay attention to the spillover effect of the associated credit risk in the supply chain to take effective risk management and control measures in a timely manner to reduce or even eliminate the adverse impact of the associated credit risk contagion in the supply chain.

\section{Conclusions and Future Research}

In this paper, we consider a two-echelon supply chain consisting of a capital-constrained supplier and a capitalconstrained retailer. The supplier provides a buy-back guarantee for the retailer's financing needs. Although the buyback guarantee mechanism partially alleviates the retailer's financing predicament, the supplier shares the credit risk of the retailer, leading to an increased default probability of the supplier. Therefore, the buy-back guarantee behavior to a certain extent reflects the contagion of the associated credit risk in the supply chain. Under the dual Stackelberg game framework of the lending institutions, supplier and retailer, the contagion mechanism of the associated credit risk in the supply chain is clarified, and mathematical models are constructed to analyze the contagion and spillover effect of the associated credit risk under the buy-back guarantee mechanism. The research results show that, in the buy-back guarantee context, the associated credit risk in the supply chain will present the contagion effect under conditions of triggering the market demand and the default thresholds of the retailer and supplier. The contagion effect is positively correlated with the buy-back rate, production costs, and loan interest rates, and it is negatively correlated with the product market price. In contrast, when the buy-back rate weakens the positive spillover effect of the associated credit risk, the larger the buy-back rate, the weaker the positive spillover effect, and the stronger the negative spillover effect. From the perspective of risk control in the supply chain situation, the lending institutions should take into consideration the relationship of the upstream and downstream enterprises in the supply chain to carry out risk control more effectively and reduce loan losses. The conclusions of this paper provide theoretical support for risk management and control of supply chain enterprises and lending institutions.

Our work has limitations. In the research presented this paper, to simplify the analysis and highlight the research focus, necessary abstraction and simplification of the model are performed. For example, the initial funds of the supplier and retailer are both zero, the retailer can obtain funds from the lending institutions under the buy-back guarantee of the supplier, the retailer's upfront payments are constant, and the information between the lending institutions and the supply chain enterprises is symmetrical, among others. The same assumption has been frequently applied in related literature, allowing us to focus on the main managerial insights. However, further loosening of these assumptions may lead to more realistic conclusions. In addition, trade credit usually exists among supply chain enterprises in reality. Our current work is designed to embed trade credit in buyback guarantee mode to study the contagion effect of the associated credit risk in the supply chain.

\section{Appendix}

See Tables 3, 4, 5, and 6.

\section{Data Availability}

The numerical analysis data used to support the findings of this study are included within the supplementary information file (appendix).

\section{Conflicts of Interest}

The authors declare that they have no conflicts of interest.

\section{Acknowledgments}

This study was supported by National Natural Science Foundation of China (Grants: 71271043 \& 71701066 \& 71671144 \& 71871447).

\section{References}

[1] K. Giesecke and S. Weber, "Credit contagion and aggregate losses," Journal of Economic Dynamics and Control, vol. 30, no. 5, pp. 741-767, 2002.

[2] K. Giesecke and S. Weber, "Cyclical correlations, credit contagion, and portfolio losses," Journal of Banking \& Finance, vol. 28, no. 12, pp. 3009-3036, 2004.

[3] Q. Wang and T. Hartmannwendels, "Credit default risk contagion modeling," Journal of Financial Research, vol. 12, no. 10, pp. 162-173, 2008.

[4] E. Beretta and S. D. Prete, "Banking consolidation and bankfirm credit relationships: the role of geographical features and 
relationship characteristics," Review of Economics and Institutions, vol. 4, no. 3, pp. 1-28, 2013.

[5] C. Raddatz, "Credit chains and sectoral comovement: does the use of trade credit amplify sectoral shocks," Review of Economics and Statistics, vol. 92, no. 4, pp. 985-1003, 2010.

[6] T. Jacobson and E. V. Schedvin, "Trace credit and the propagation of corporate failure: an empirical analysis," Econometrica, vol. 83, no. 4, pp. 1315-1371, 2015.

[7] X.-F. Xie, Y. Yang, Y.-M. Zhou, and Z.-F. Zhou, “The clustering analysis on data and lending strategy of supply chain with information asymmetry method," Cluster Computing, vol. 1, no. 1, pp. 1-9, 2017.

[8] G. Tamakoshi and S. Hamori, "Transmission of stock prices amongst European countries before and during the Greek sovereign debt crisis," Economics Bulletin, vol. 31, no. 4, pp. 3339-3353, 2011.

[9] J. Nikkinen, V. Piljak, and J. Äijö, "Baltic stock markets and the financial crisis of 2008-2009," Research in International Business and Finance, vol. 26, no. 3, pp. 398-409, 2012.

[10] M. Billo, M. Getmansky, A. W. Lo, and L. Pelizzon, "Econometric measures of connectedness and systemic risk in the finance and insurance sectors," Journal of Financial Economics, vol. 104, no. 3, pp. 535-559, 2012.

[11] M. H. Tong, G. J. Zhang, and Y. G. Luan, "A study on SMEs financing and its risk spillover effect on shadow banking in China," Review of Investment Studies, vol. 409, no. 3, pp. 52-67, 2012.

[12] P. H. Gao and Y. L. Pan, "Financial interlinkages and contagion risk in the interbank market in China," Journal of Industrial Engineering and Engineering Management, vol. 26, no. 4, pp. 162-168, 2012.

[13] T. Q. Chen, L. Wang, and Q. R. Zeng, "Research on counterparty risk contagion based on bank-enterprise credit network," Financial Development Research, vol. 12, no. 2, pp. 32-38, 2019.

[14] R. A. Jarrow and S. M. Turnbull, "Pricing derivatives on financial securities subject to credit risk," Journal of Finance, vol. 50, no. 1, pp. 53-85, 1995.

[15] J. A. Buzacott and R. Q. Zhang, "Inventory management with asset-based financing," Management Science, vol. 50, no. 9, pp. 1274-1292, 2004.

[16] X. H. Yi and Z. F. Zhou, "The banks credit decision mechanism of inventory financing with two Stackelberg models," Systems Engineering, vol. 29, no. 12, pp. 1-6, 2011.

[17] V. Padmanabhan and I. P. L. Png, "Returns policies: make money by making good," MIT Sloan Management Review, vol. 37, no. 1, pp. 65-72, 1995.

[18] A. H. Lau and H. Lau, "The newsboy problem with pricedependent demand distribution," IIE Transactions, vol. 20, no. 2, pp. 168-175, 1988.

[19] C.-C. Hsieh and Y.-T. Lu, "Manufacturer's return policy in a two-stage supply chain with two risk-averse retailers and random demand," European Journal of Operational Research, vol. 207, no. 1, pp. 514-523, 2010.

[20] F. J. Arcelus, S. Kumar, and G. Srinivasan, "Channel coordinaton with manufacturer's return policies within a newsvendor framework," Operation Research, vol. 9, no. 3, pp. 279-297, 2011.

[21] R. Ruiz-Benitez and A. Muriel, "Consumer returns in a decentralized supply chain," International Journal of Production Economics, vol. 147, no. 1, pp. 573-592, 2014.

[22] X. F. Chen, D. L. Zhu, and W. J. Ying, "Financial and operation decisions in budget-constrained supply chain," Journal of Management Sciences in China, vol. 11, no. 3, pp. 70-77, 2008.
[23] P. Vandenberg, "Adapting to the financial landscape: evidence from small firms in Nairobi," World Development, vol. 31, no. 11, pp. 1829-1843, 2003.

[24] M. Burkart and T. Ellingsen, "In-kind finance: a theory of trade credit," American Economic Review, vol. 94, no. 3, pp. 569-590, 2004.

[25] M. Giannetti, M. Burkart, and T. Ellingsen, "What you sell is what you lend? Explaining trade credit contracts," Review of Financial Studies, vol. 24, no. 4, pp. 1261-1298, 2011.

[26] P. Kouvelis and W. Zhao, "Financing the newsvendor: supplier vs. bank, and the structure of optimal trade credit contracts," Operations Research, vol. 60, no. 3, pp. 566-580, 2012.

[27] P. Kouvelis and W. Zhao, "Supply chain contract design under financial constraints and bankruptcy costs," Management Science, vol. 62, no. 8, pp. 2341-2357, 2016.

[28] C. S. Tang, S. A. Yang, and J. Wu, "Sourcing from suppliers with financial constraints and performance risk," Manufacturing \& Service Operations Management, vol. 20, no. 1, pp. 70-84, 2018.

[29] B. Jing and A. Seidmann, "Finance sourcing in a supply chain," Decision Support Systems, vol. 58, no. 1, pp. 15-20, 2014.

[30] P. Kouvelis and W. Zhao, "Who should finance the supple chain? impact of credit ratings on supply chain decisions," Manufacturing and Service Operations Management, vol. 20, no. 1, pp. 19-35, 2018.

[31] J. E. Stiglitz and A. Weiss, "Credit rationing in markets with imperfect information," American Economic Review, vol. 71, no. 3, pp. 393-410, 1981.

[32] J. S. Lv, "On financing constraints of small and medium enterprises," Journal of Financial Research, vol. 425, no. 11, pp. 115-123, 2015.

[33] Y. F. Lin and X. F. Sun, "Information, informal financeand SME financing," Economic Research Journal, vol. 12, no. 7, pp. 35-44, 2005.

[34] L. H. Meyer, "The present and future roles of banks in small business finance," Journal of Banking \& Finance, vol. 22, no. 6-8, pp. 1109-1116, 1998.

[35] Y. F. Lin and Y. J. Li, "Promoting the growth of medium and small-sized enterprises through the development of dedium and small-sized financial Institutions," Economic Research, vol. 12, no. 11, pp. 10-18, 2001.

[36] D. J. Kisgen and P. E. Strahan, "Do regulations based on credit ratings: affect a firm's cost of capital?” Review of Financial Studies, vol. 23, no. 12, pp. 4324-4347, 2010.

[37] R. Hartley-Urquhart, "Managing the financial supply chain," Supply Chain Management Review, vol. 10, 2006.

[38] Y. F. Hu and S. Q. Huang, "Supply chain finance: background, innovation and concept definition," Journal of Financial research, vol. 12, no. 8, pp. 194-206, 2009.

[39] S. A. Yang and J. R. Birge, "Trade credit, risk sharing, and inventory financing portfolios," Management Science, vol. 64, no. 8, pp. 3469-3970, 2018.

[40] J. Tirole, The Theory of Corporate Finance, Princeton University Press, Princeton, NJ, USA, 2006.

[41] T. Jia, Y. Zheng, and J. L. Chang, "Inventory model for deteriorating item under two-level trade credit policy advance payments from customers," China Journal of Management Science, vol. 21, no. 6, pp. 80-87, 2012.

[42] Y. Yang and Z. F. Zhou, "Credit risk of supply chain based on credit behavior," Systems Engineering, vol. 29, no. 12, pp. 35-39, 2011. 
[43] X. Chen and A. Wang, "Trade credit contract with limited liability in the supply chain with budget constraints," Annals of Operations Research, vol. 196, no. 1, pp. 153-165, 2012.

[44] V. Cuñat, "Trade credit: suppliers as debt collectors and insurance providers," Review of Financial Studies, vol. 20, no. 2, pp. 491-527, 2007.

[45] J. Zhou and H. Groenevelt, "Impacts of financial collaboration in a three-party supply chain," Working Paper, The Simon School, University of Rochester, Rochester, NY, USA.

[46] V. Babich and P. Kouvelis, "Introduction to the special issue on research at the interface of finance, operations, and risk management (iFORM): recent contributions and future directions," Manufacturing and Service Operations Management, vol. 20, no. 1, pp. 1-18, 2018.

[47] R. Cressy and C. Olofsson, "The financial conditions for swedish SMEs: survey and research agenda," Small Business Economics, vol. 9, no. 2, pp. 179-194, 1997. 


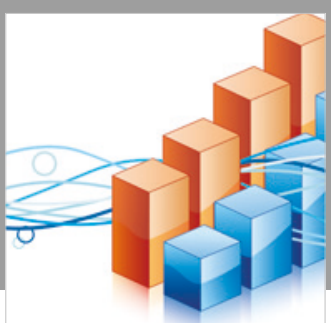

Advances in

Operations Research

\section{-n-m}
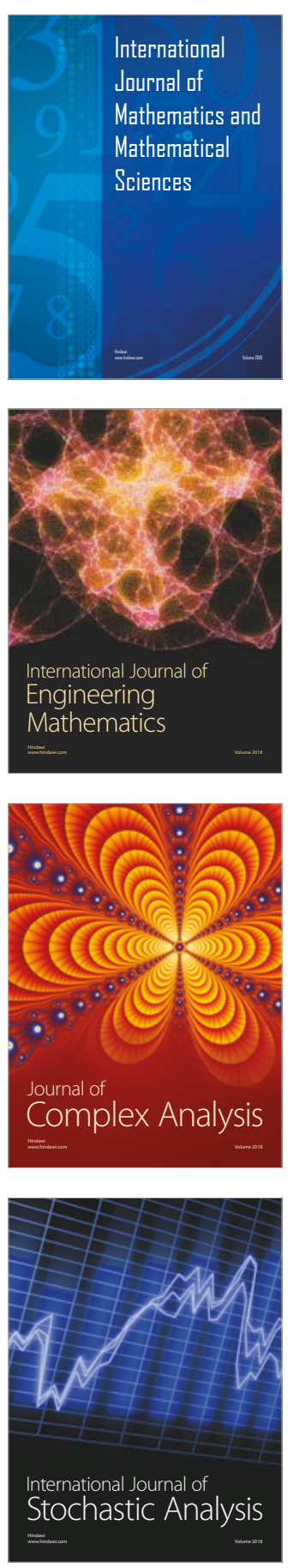
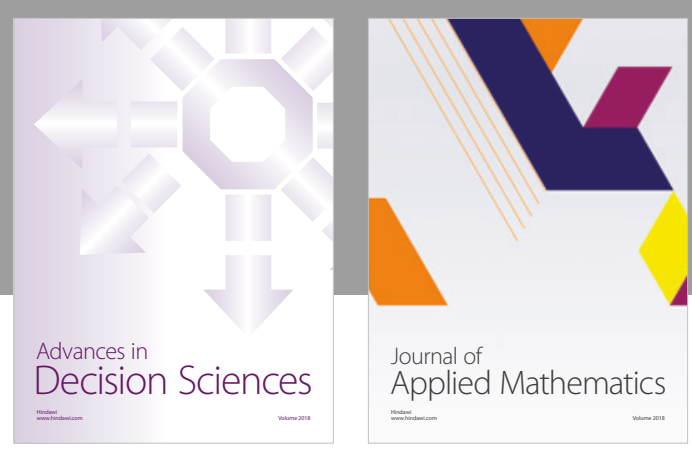

Journal of

Applied Mathematics
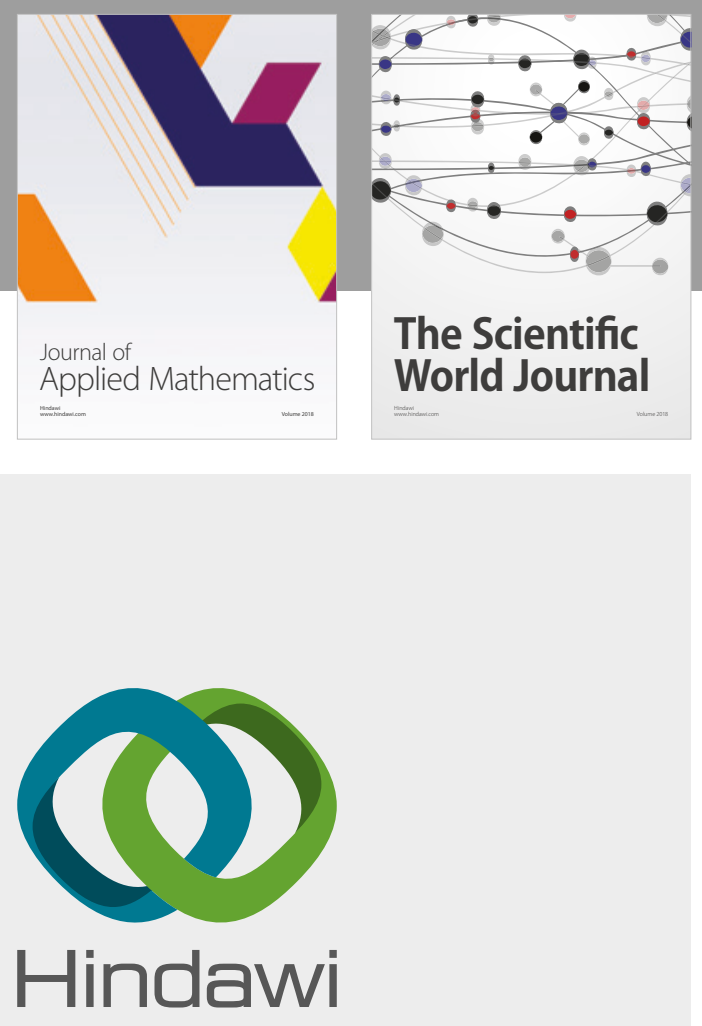

Submit your manuscripts at

www.hindawi.com

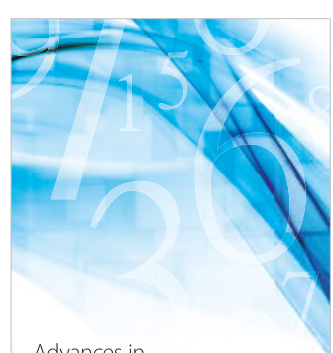

Advances in
Numerical Analysis
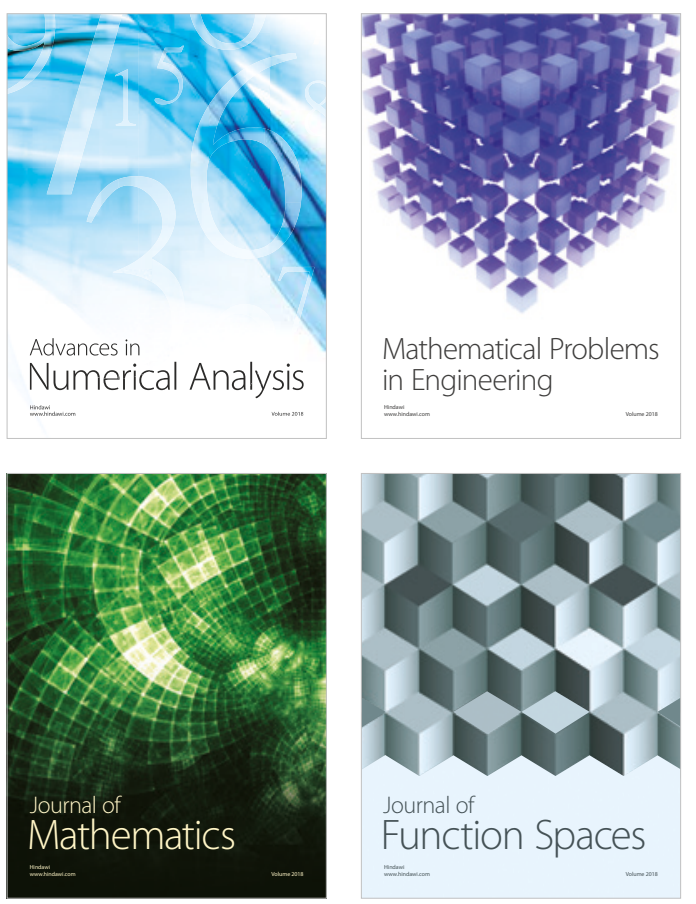

Mathematical Problems in Engineering

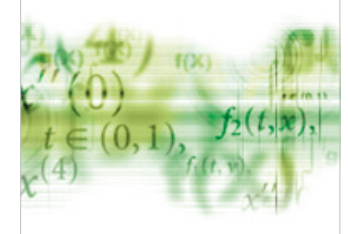

International Journal of

Differential Equations

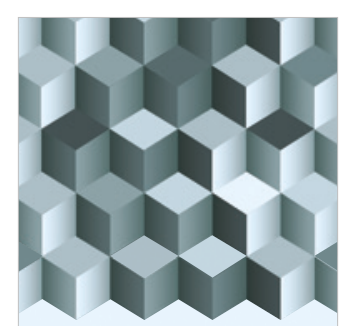

Journal of

Function Spaces

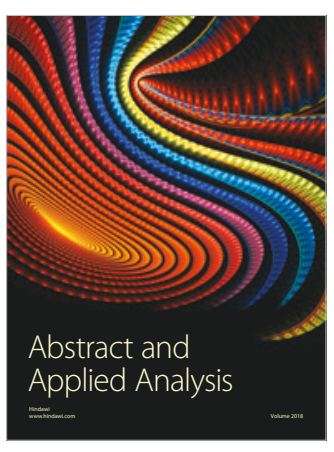

The Scientific

World Journal

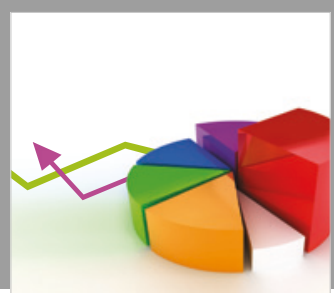

Journal of

Probability and Statistics
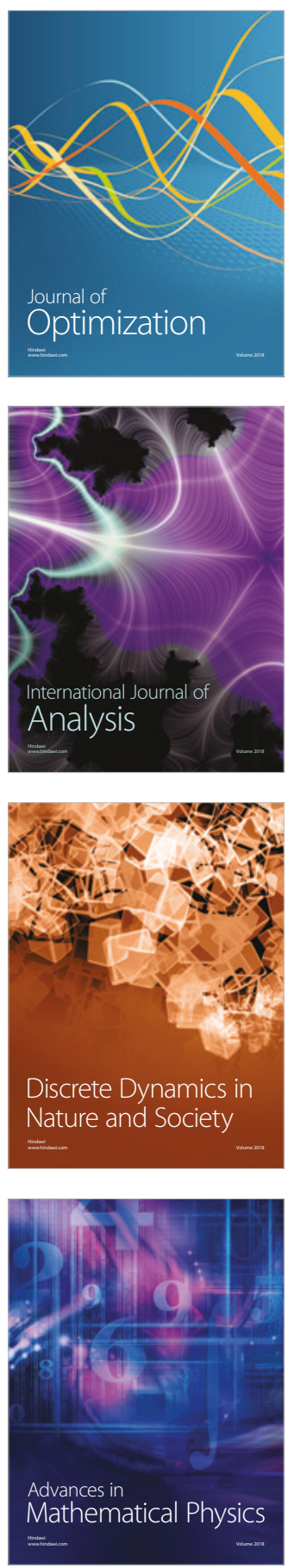